Research Article

\title{
New Structural Seismic Isolation for Nuclear Containment Structures
}

\author{
Azer A. Kasimzade $\mathbb{D}^{1},{ }^{1}$ Obaidullah Abrar ${ }^{D},{ }^{1}$ Mehmet Kuruoglu, ${ }^{2}$ and Gencay Atmaca ${ }^{3}$ \\ ${ }^{1}$ Department of Civil Engineering, Ondokuz Mayis University, Samsun 55139, Turkey \\ ${ }^{2}$ Department of Civil Engineering, Dokuz Eylul University, İmir 35160, Turkey \\ ${ }^{3}$ Provincial Directorate of Disaster and Emergency, Samsun 55200, Turkey \\ Correspondence should be addressed to Azer A. Kasimzade; azer@omu.edu.tr
}

Received 21 April 2019; Accepted 17 January 2020; Published 20 February 2020

Academic Editor: Arkady Serikov

Copyright $\odot 2020$ Azer A. Kasimzade et al. This is an open access article distributed under the Creative Commons Attribution License, which permits unrestricted use, distribution, and reproduction in any medium, provided the original work is properly cited.

\begin{abstract}
The new Structural Seismic Isolation System (SSIS) intends to provide high safety for important structures such as nuclear power plants, offshore oil platforms, and high-rise buildings against near-fault and long-period earthquakes. The presented SSIS structure foot base and foundation contact surfaces have been designed as any curved surfaces (spherical, elliptical, etc.) depending on the earthquake-soil-superstructure parameters, and these contact surfaces have been separated by using elastomeric (lead core rubber or laminated rubber bearings with up to 4-second period) seismic isolation devices. It would allow providing inverse pendulum behavior to the structure. As a result of this behavior, the natural period of the structure will possess greater intervals which are larger than the predominant period of the majority of the possible earthquakes including near-fault zones. Consequently, the structure can maintain its serviceability after the occurrence of strong and long-period earthquakes. This study has investigated the performance of the SSIS for the nuclear containment (SSIS-NC) structure. The finite element model of SISS-NC structure has been developed, and nonlinear dynamic analysis of the model has been conducted under the strong and long-period ground motions. The results have been presented in comparison with the conventional application method of the seismic base isolation devices for nuclear containment (CAMSBID-NC) and fixed base nuclear containment (FB-NC) structures. The base and top accelerations, effective stress, and critical shear stress responses of the SSIS-NC structure are $48.67 \%, 36.70 \%$, and $32.60 \%$ on average lower than those of CAMSBID-NC structure, respectively. The result also confirms that the SSIS-NC structure did not cause resonant vibrations under long-period earthquakes. On the other hand, there is excessive deformation in the isolation layers of CAMSBID-NC structure.
\end{abstract}

\section{Introduction}

Seismic base isolation is indicated as a reliable tool for the protection of structures against strong earthquakes [1,2], and there are more than seven thousand seismically isolated buildings around the world. On the other hand, the number of active seismically isolated nuclear power plants is very low (only six) and they are located in the low seismic hazard risk regions. All are pressurized water reactors (PWR), four of them located in Cruas Meysse (France) and the remaining two in Koeberg (South Africa) [3]. The main reasons for limited usage of seismic isolation are related to decline of nuclear power plant construction from 1980 to 2010, construction of NPPs in regions with low seismic hazard risks, and lack of proper codes/standards for the design of
NPPs with seismic isolation systems [4]. Another reason for sparse usage of the seismic isolation system for NPPs could be related to the fact that water reactors are the most common which are stiff structures containing rigid internal components with intrinsic robustness enough to overcome low ground motions (0.1 g peak) [5]. During the last two decades, various institutions such as the American Society of Civil Engineers published codes regarding analysis, design, and safety issues of nuclear structures called ASCE 4-16 [6]; the older version was included in ASCE 43-05 [7]. Based on this code, elastomeric (low damping and lead rubber) and friction pendulum sliding isolator are suggested for seismic protection of nuclear facilities [4]. The French Association for nuclear steam system supply equipment construction rules, AFCEN, developed regulations for the 
design of base-isolated structures using elastomeric bearings [8]. The Atomic Energy Research Institute of Korea aimed to develop a seismic design standard for seismic base-isolated nuclear power plant structures [3].

The Fukushima Daiichi nuclear disaster revealed the vulnerability of the nuclear power plants against strong earthquakes causing serious causalities and environmental problems [9]. There are several studies regarding the seismic isolation of nuclear installations. For instance, Ostrovskaya and Rutman proposed a support-pendulum seismic isolation system for seismic protection of NPP structures; this system aims to isolate the vibration and shocks using pendulum bars and plastic dampers [10]. Studies of Whittaker et al. and Medel-Vera et al. on seismic protection of nuclear power plants also can be noted $[4,11,12]$ as efforts to develop a seismic design standard for seismically isolated nuclear power plants in the United Kingdom. Kasimzade et al. [13-15] proposed and developed a new structural seismic isolation system named Structural Seismic Isolation System (SSIS) against strong and long-period earthquake ground motions, and it aims to eliminate the limitation and vulnerability of the conventional elastomeric (lead rubber or laminated rubber) base-isolated structures for the same excitations [16]. The SSIS system provides the possibility of keeping the natural period of the structure in a larger interval which is greater than the predominant period of the majority of possible earthquakes (including near-fault pulse) using currently existing conventional elastomeric isolators with up to 4 sec period. In this study, the finite element simulation of the dynamic performance of the SSIS with the spherical structure foot base and foundation contact surfaces for nuclear containment (SSIS-NC) structure was presented in comparison with a conventional application method of the seismic base isolation devices for nuclear containment (CAMSBID-NC) and fixed-base nuclear containment (FB-NC) structures, respectively.

1.1. Fundamentals of SSIS. The main aim of the SSIS is to keep the period of structure beyond the period of the earthquake. This aim is approached by building structure foot base, and foundation contact surfaces have been designed as any curved surface (spherical, elliptical, etc.) depending on the earthquake-soil-superstructure parameters and these contact surfaces have been separated by using elastomeric (lead core rubber or laminated rubber bearings) seismic isolation devices. It would allow the curved surface structure foot base to turn around the gyration center through rubber bearing contact and maintain similar behavior to the superstructure. This will allow structures to overcome strong earthquakes including long-period and near-fault pulse. The governing equation and the mathematical model of the SSIS with the spherical structure foot base and foundation contact surfaces (see Figure 1) have been presented as follows [13-15]:

$$
\begin{aligned}
{[m]\{\ddot{u}\}+[c]\{\dot{u}\}+[k]\{u\} } & =\left\{F_{\ddot{u}_{g}}\right\}, \\
\ddot{\varphi} C_{2}+\dot{\varphi} C_{1}-\varphi C_{01} g+\rho_{2} F_{k b}(\varphi) & =\ddot{u}_{g} C_{02},
\end{aligned}
$$

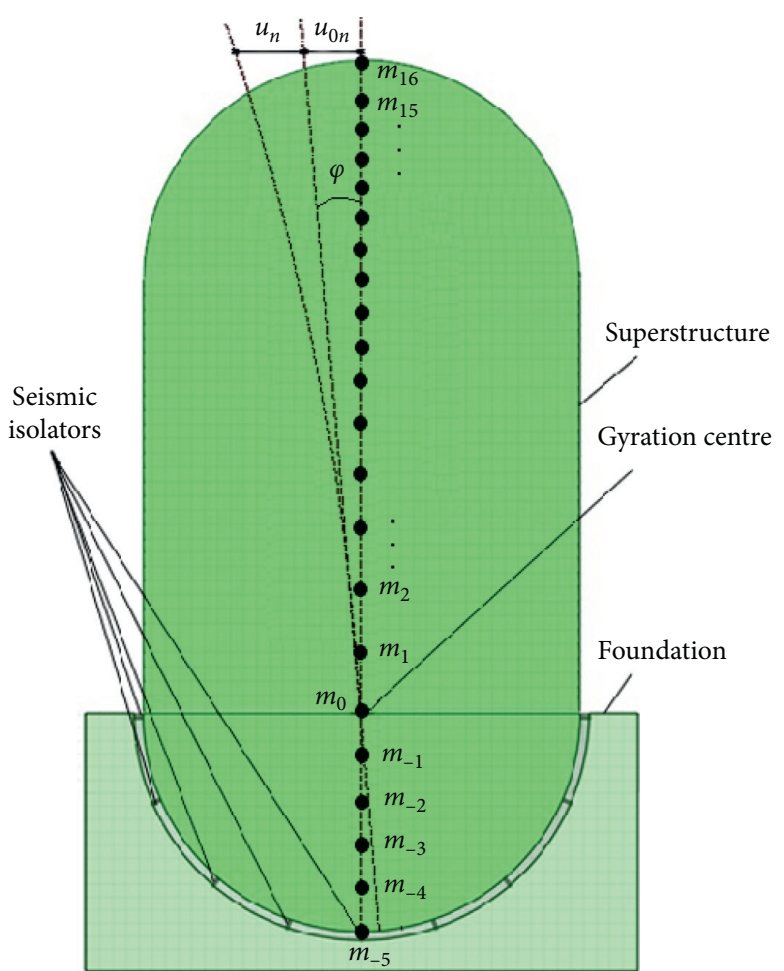

FIgURE 1: General working mechanism schema of the SSIS-NC system.

with

$$
\begin{aligned}
F_{k b} & =\alpha k_{b} u_{b}+(1-\alpha) F_{y} Z, \\
F_{y} & =Q+\alpha k_{b} u_{y}, \\
\dot{Z} & =\left[a \dot{u}_{b}-\beta\left|\dot{u}_{b}\right| Z|Z|^{n-1}-\gamma \dot{u}_{b}|Z|^{n}\right] u_{y}^{-1}, \\
C_{1} & =\rho_{2}^{2}\left(c_{d}+c_{b}\right),
\end{aligned}
$$

where $[m],[c]$, and $[k]$ are the mass, Rayleigh damping, and stiffness matrix of the superstructure, respectively, and were composed by FEM [17]. $u$ is the relative displacement vector of the superstructure of the deformed state. $\dot{u}$ and $\ddot{u}$ are the velocity and acceleration vector, respectively. $F_{\ddot{u} g}$ stands for seismic force:

$$
\begin{aligned}
&\left\{F_{\ddot{u}_{g}}\right\}=\left\{\begin{array}{c}
m_{1}\left(\ddot{u}_{g}-\ddot{u}_{01}\right) \\
m_{2}\left(\ddot{u}_{g}-\ddot{u}_{02}\right) \\
\vdots \\
m_{i}\left(\ddot{u}_{g}-\ddot{u}_{0 i}\right) \\
\vdots \\
m_{n}\left(\ddot{u}_{g}-\ddot{u}_{0 n}\right)
\end{array}\right\}, \\
&\left\{\ddot{u}_{0}\right\}=\left\{\begin{array}{c}
\ddot{u}_{01} \\
\ddot{u}_{02} \\
\vdots \\
\ddot{u}_{0 i} \\
\vdots \\
\ddot{u}_{0 n}
\end{array}\right\}=\left\{\begin{array}{c}
h_{1} \\
h_{2} \\
\vdots \\
h_{i} \\
\vdots \\
h_{n}
\end{array}\right\} \ddot{\varphi},\{u\}=\left\{\begin{array}{c}
u_{1} \\
u_{2} \\
\vdots \\
u_{i} \\
\vdots \\
u_{n}
\end{array}\right\},
\end{aligned}
$$


with

$$
\begin{aligned}
& u_{0 i}=\varphi h_{0 i}, \\
& \ddot{u}_{0 i}=\ddot{\varphi} h_{i}, u_{0 i}=\varphi \rho_{2} .
\end{aligned}
$$

Here, $\varphi$ represents the absolute rigid structure's rotation angle around the gyration center, $\ddot{u}_{g}$ is the ground motion excitation, $F_{c 0}=c_{b} \rho_{2} \varphi$ is the total damping, and $F_{k b}$ is the total stiffness forces of the seismic isolator deployed in the SSIS which possesses total damping coefficient and spherical radius $\left(\rho_{2}\right) . F_{c \text { e eq }}=c_{d} \rho_{2} \dot{\varphi}$ represents the sum of external dampers' equal damping force which contains the $c_{\mathrm{d}}$ (damping coefficient), and $\varphi$ is the solution of Equation (2):

$$
\begin{aligned}
C_{2} & =2\left(\sum_{i=1, n} m_{i} h_{i}^{2}+\sum_{j=i, m} m_{0 j} h_{0 j}^{2}\right), \\
C_{01} & =\sum_{i=1, n} m_{i} h_{i}-\sum_{j=i, m} m_{0 j} h_{0 j}, \\
C_{02} & =\sum_{i=1, n} m_{i} h_{i}-\sum_{j=i, m} m_{0 j} h_{0 j} .
\end{aligned}
$$

Here, $h_{i}(i=1, n)$ is the $z$ distance of the superstructure's $i$-th mass $m_{i}$ from the gyration center; $m_{0 j}$ and $h_{0 j}(j=1, m)$ are the similar parameters for the underground part of the SSIS. The lateral displacement of the superstructure's base is indicated by $u_{b}$ which correlates to the contact surface of the foundation. $u_{y}$ stands for the yield displacement, $k_{b}$ for the total stiffness of the isolators, and $\alpha$ for the postyielding to preyielding stiffness ratio of seismic isolators commonly taken as 0.1 . The ratios $d_{r}=u_{y b 2} / u_{y}=$ about 10 and $f_{r}=F_{y b 2} /$ $F_{y}=$ about 2 , respectively, as described in Figure 2. The parameter $\dot{Z}$ refers to the dimensionless hysteresis displacement component that satisfies the nonlinear first-order $[18,19]$ differential equation (5). $F_{y}$ and $Q$ refer to the yield and characteristic strengths of the seismic isolator, respectively. By defining the $F_{0}$ parameter as presented in equation (10) with regard to the total weight of the structure $W$, the yield strength of the seismic isolator can be normalized:

$$
F_{0}=\frac{F_{y}}{W} .
$$

In some references, normalized stiffness has been expressed as

$$
\begin{aligned}
f_{0} & =\frac{Q}{W}, \\
W & =g m_{t}, \\
m_{t} & =m_{b}+\sum_{i=1}^{n} m_{i},
\end{aligned}
$$

where $m_{i}, m_{b}$, and $m_{t}$ are the mass of the story, base slab, and total mass of the building respectively.

In equation (5), $\beta, a, n$, and $\gamma$ are the dimensionless parameters and affect the shape of the hysteresis loop; the value of these parameters is predicted through experiments. Here, the value of the abovementioned parameters are taken

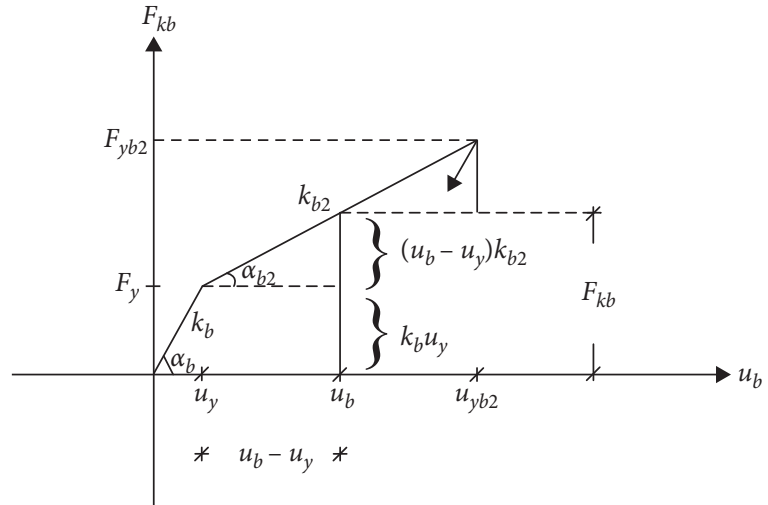

FIGURE 2: Illustration of the hysteresis loop of the LCRB isolator and its geometric ratios [13].

as $n=2 ; a=1$; and $(\beta+\gamma) / a=1$. The model of equation (5) decreases to a viscoplasticity model; in equation (5), $u_{y}$ refers to the yield displacement. The base and top absolute displacement and acceleration behavior of the SSIS-NC structure are described through the following equation:

$$
\begin{aligned}
& u_{n, \text { abs. }}=\left|-u_{n}-u_{0 n}\right|=u_{\text {top, abs, }} \\
& \ddot{u}_{n, \text { abs. }}=\left|-\ddot{u}_{g}-\ddot{u}_{n}-\ddot{u}_{0 n}\right|=u_{\text {top, abs? }}, \\
& u_{b, \text { abs. }}=\left|-u_{g}+u_{\mathrm{b}}\right|, \\
& \ddot{u}_{b, \text { abs. }}=\left|-\ddot{u}_{g}+\ddot{u}_{\mathrm{b}}\right|,
\end{aligned}
$$

where, $u_{b}, u_{n}, \ddot{u}_{b}$, and $\ddot{u}_{n}$ are the base and top relative displacement and acceleration and $u_{0 n}$ and $\ddot{u}_{0 n}$ are the top relative displacement and acceleration of the SSIS-NC structure as a rigid body.

Assessment of the SSIS-NC structure has been conducted by MATLAB and Simulink programming tools using the presented governing equations by Kasimzade et al. [13-15] in the following section.

1.2. Assessment of SSIS for Nuclear Containment Structure. A numerical assessment of the SSIS structure is presented with an example of reinforced concrete nuclear containment structure $[20,21]$. The structure is formed of a semispherical dome, a cylindrical shell wall, and at the bottom, a base-mat slab (see Figure 3(d)). The cylinder is $47.34 \mathrm{~m}$ tall with an inside diameter of $39.0 \mathrm{~m}$ and a thickness of $0.90 \mathrm{~m}$. The base-mat slab has a mean thickness of $5.50 \mathrm{~m}$. The dome is $0.90 \mathrm{~m}$ thick with an outer radius of $18.50 \mathrm{~m}$. The total height of the superstructure is $65.840 \mathrm{~m}$ from the base mat. Material properties of reinforced concrete are presented in Table 1; the grade of the concrete is C50. The cooling system of the nuclear containment is located at the base of the structure. The distribution of the mass for SSIS-NC, CAMSBID-NC, and FB-NC structures based on references $[20,21]$ are presented in Table 2, respectively.

Assuming that the predominant period of the earthquakes in the area where FB-NC, CAMSBID-NC, and SSISNC structures are about 11 seconds, SSIS's required total 


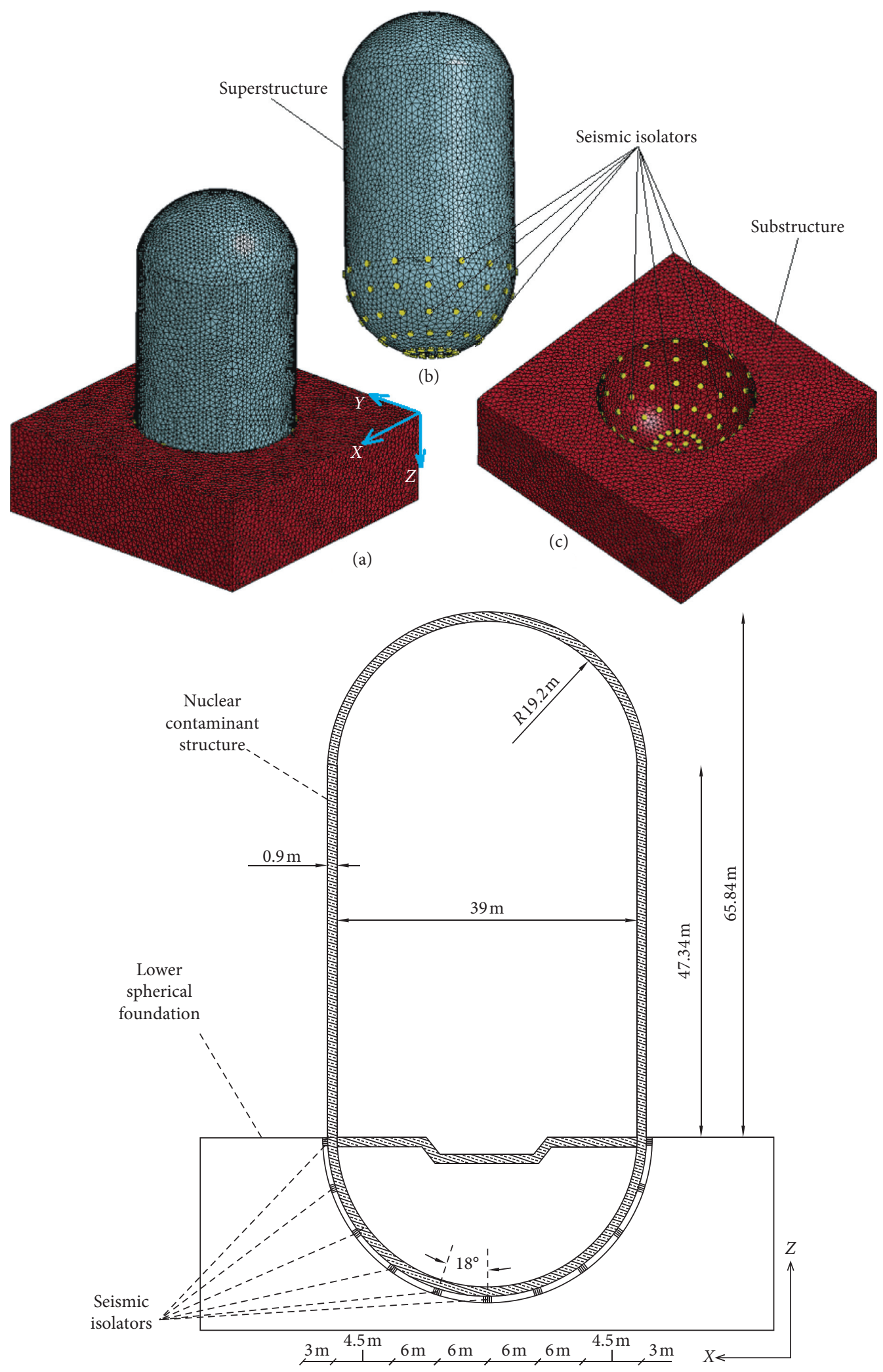

(d)

FIGURE 3: Overall view and illustration of the finite element model of the nuclear containment structure with the SSIS (a-c); the position of deployed seismic isolator and dimensions of SSIS-NC structure (d). 
TABLE 1: Material properties of reinforced concrete [21].

Density $\left(\mathrm{kg} / \mathrm{m}^{3}\right)$

Tensile strength $\left(\mathrm{N} / \mathrm{m}^{2}\right)$

$1.740 E+05$

Young's modulus $\left(\mathrm{N} / \mathrm{m}^{2}\right)$

$2.011 E+10$

Shear modulus $\left(\mathrm{N} / \mathrm{m}^{2}\right)$

$0.837 E+10$

TABLE 2: Distribution of the masses for SSIS-NC, CAMSBID-NC, and FB-NC structures.

\begin{tabular}{|c|c|c|c|c|c|c|c|}
\hline \multirow{2}{*}{\multicolumn{2}{|c|}{$\frac{\text { Node elevation }(\mathrm{m})}{-20.00}$}} & \multicolumn{2}{|c|}{ SSIS-NC } & \multicolumn{2}{|c|}{ CAMSBID-NC } & \multicolumn{2}{|c|}{ FB-NC } \\
\hline & & $m(-5)$ & $2.00 E+06$ & & - & & - \\
\hline-16.00 & \multirow{4}{*}{ Undergr. part } & $m(-4)$ & $6.83 E+05$ & & - & & - \\
\hline-12.00 & & $m(-3)$ & $1.09 E+06$ & & - & & - \\
\hline-8.00 & & $m(-3)$ & $1.22 E+06$ & & - & & - \\
\hline-4.00 & & $m(-1)$ & $1.30 E+06$ & & - & & - \\
\hline 0.00 & \multirow{18}{*}{ Superstructure } & $m(0)$ & $1.07 E+06$ & Isolation layer & $1.07 E+06$ & & - \\
\hline 5.182 & & $m(1)$ & $1.91 E+06$ & $m(1)$ & $1.91 E+06$ & $m(1)$ & $1.91 E+06$ \\
\hline 8.534 & & $m(2)$ & $1.39 E+06$ & $m(2)$ & $1.39 E+06$ & $m(2)$ & $1.39 E+06$ \\
\hline 11.89 & & $m(3)$ & $1.65 E+06$ & $m(3)$ & $1.65 E+06$ & $m(3)$ & $1.65 E+06$ \\
\hline 14.94 & & $m(4)$ & $1.26 E+06$ & $m(4)$ & $1.26 E+06$ & $m(4)$ & $1.26 E+06$ \\
\hline 17.98 & & $m(5)$ & $1.33 E+06$ & $m(5)$ & $1.33 E+06$ & $m(5)$ & $1.33 E+06$ \\
\hline 21.34 & & $m(6)$ & $2.09 E+06$ & $m(6)$ & $2.09 E+06$ & $m(6)$ & $2.09 E+06$ \\
\hline 28.04 & & $m(7)$ & $3.60 E+06$ & $m(7)$ & $3.60 E+06$ & $m(7)$ & $3.60 E+06$ \\
\hline 38.71 & & $m(8)$ & $2.84 E+06$ & $m(8)$ & $2.84 E+06$ & $m(8)$ & $2.84 E+06$ \\
\hline 41.76 & & $m(9)$ & $2.00 E+06$ & $m(9)$ & $2.00 E+06$ & $m(9)$ & $2.00 E+06$ \\
\hline 44.81 & & $m(10)$ & $2.01 E+06$ & $m(10)$ & $2.01 E+06$ & $m(10)$ & $2.01 E+06$ \\
\hline 52.43 & & $m(11)$ & $2.76 E+06$ & $m(11)$ & $2.76 E+06$ & $m(11)$ & $2.76 E+06$ \\
\hline 60.05 & & $m(12)$ & $2.76 E+06$ & $m(12)$ & $2.76 E+06$ & $m(12)$ & $2.76 E+06$ \\
\hline 65.84 & & $m(13)$ & $1.24 E+06$ & $m(13)$ & $1.24 E+06$ & $m(13)$ & $1.24 E+06$ \\
\hline 60.05 & & $m(12)$ & $2.76 E+06$ & $m(12)$ & $2.76 E+06$ & $m(12)$ & $2.76 E+06$ \\
\hline \multirow[t]{3}{*}{65.84} & & $m(13)$ & $1.24 E+06$ & $M(13)$ & $1.24 E+06$ & $m(13)$ & $1.24 E+06$ \\
\hline & & Total superstructure & $3.08 E+07$ & Total superstructure & $3.08 E+07$ & Total superstructure & $3.05 E+07$ \\
\hline & & Total structure & $3.82 E+07$ & Total structure & $3.19 E+07$ & & \\
\hline
\end{tabular}

${ }^{*}$ The masses are in $\mathrm{kg}$.

elastomeric isolator horizontal stiffness for the first approximation was defined by equation (2) in case of free vibration as $k_{b}=8.6834 E+7 \mathrm{~N} / \mathrm{m}$. Other parameters of the elastomeric isolator such as period, damping coefficient, and damping ratio were defined as $T_{b}=4 \mathrm{~s}, C_{b}=1.6169 E+7 \mathrm{Ns} /$ $\mathrm{m}^{2}$, and $\xi_{b}=0.15$, respectively.

Based on the above SSIS-NC structure's parameters and using governing equations for the SSIS from the previous section, the SSIS-NC structure's performance was preliminarily assessed to Tohoku 2011 Earthquake $X$-direction acceleration excitation, and base acceleration responses are presented in Figure 4.

As presented in Figure 4, the base-level acceleration of the SSIS-NC (about four times) was significantly reduced. Based on preliminary design parameters and assessment results presented in this section, detailed finite element modeling of the SSIS-NC structure compared with FB-NC and CAMSBID-NC structures are presented in the following section.

\section{Finite Element Model of Nuclear Containment Structure with SSIS}

The finite element model of the nuclear containment structure with the SSIS has been prepared using LS-DYNA

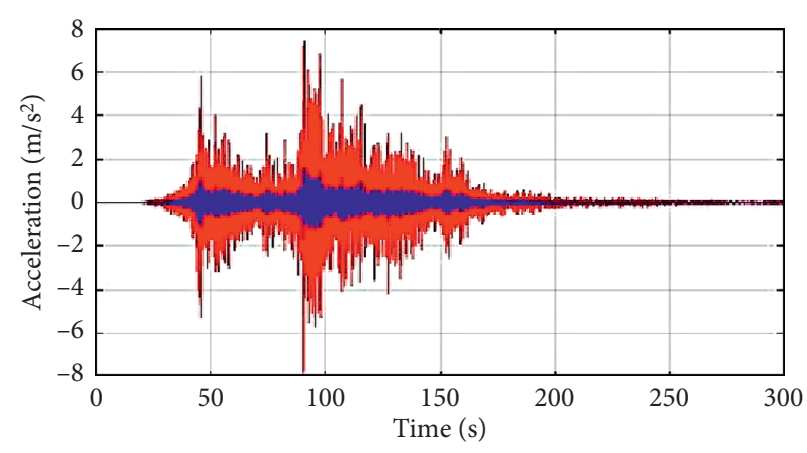

FIgURE 4: Base acceleration responses of SSIS-NC structure (blue) in $X$-direction under the effect of the Tohoku earthquake (red).

software; in this model, solid and discrete beam elements have been used [22]. Fully integrated ten-node tetrahedron solid elements [23] have been selected for modeling the structure base and the superstructure of the SSIS-NC model. The size of the solid mesh ranges between 0.7 and $2 \mathrm{~m}$. The elastomeric (lead core rubber bearing) seismic isolators have been modeled using discrete beam elements that exhibit nonlinear characteristics of elastomeric seismic isolators $[23,24]$. The size of the discrete beam element is $0.5 \mathrm{~m}$ (see 


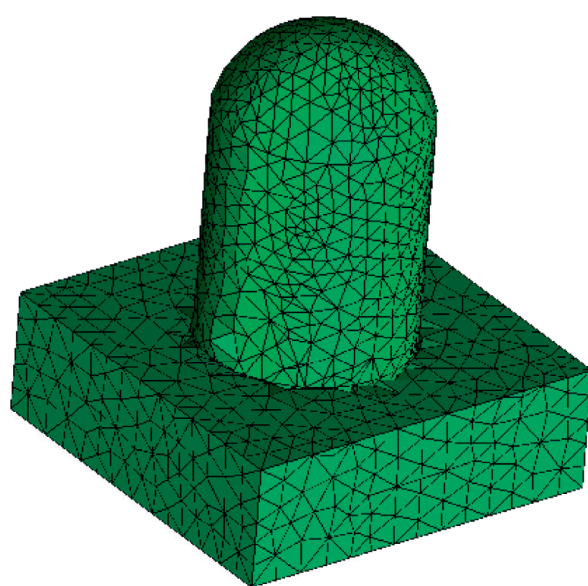

(a)

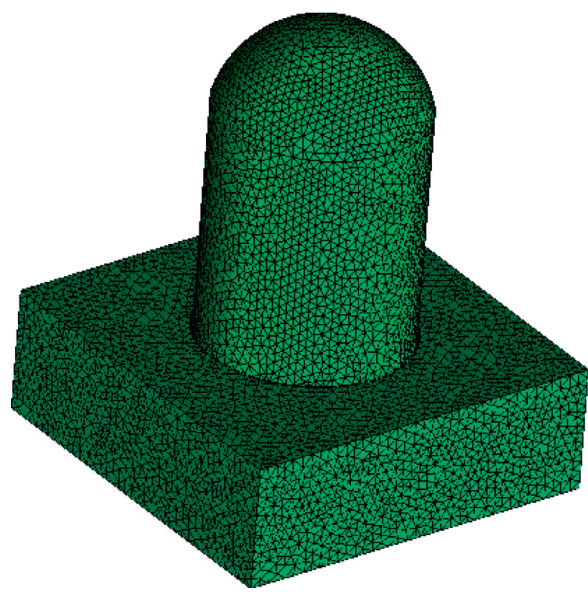

(c)

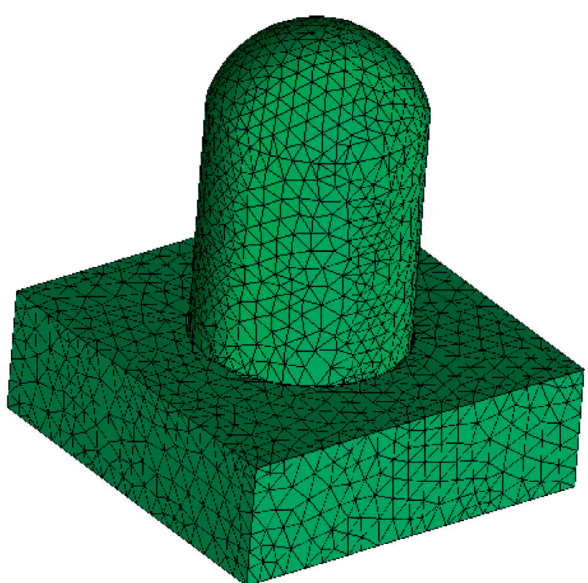

(b)

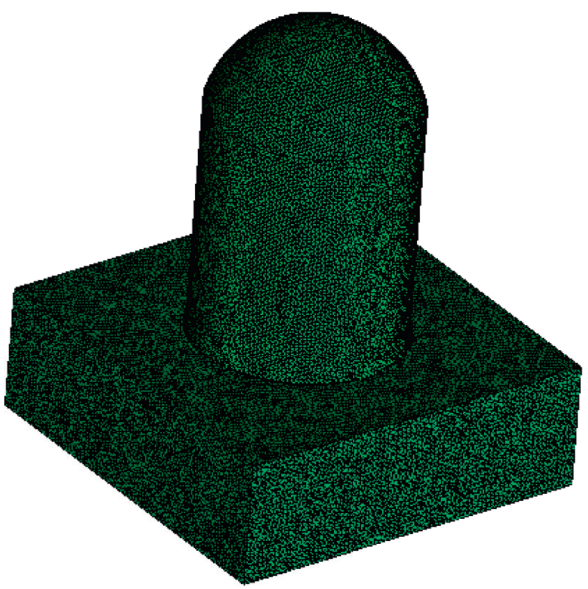

(d)

Figure 5: Nuclear containment FE model maximum mesh sizes: (a) $5.5 \mathrm{~m}$; (b) $3.5 \mathrm{~m}$; (c) $2 \mathrm{~m}$; (d) $1 \mathrm{~m}$.

Figure 3). The result of the finite element analysis is in conformity with the numerical assessment conducted with MATLAB programming presented in Section 1.2.

The mesh of the finite element model has been selected through a process of mesh convergence study. It is obvious that finer meshes procure more accurate results, but the finer the mesh becomes, the more the time and computer capacity needed for conducting the dynamic analysis. Figure 5 presents the different sizes of the meshes which have been proposed for the nuclear containment structure. Figures 5(a)-5(d) have a maximum mesh size of 5.5, 3.5, 2, and 1 meters, respectively. In this study, the third option (Figure 5(c)) has been deemed as an optimum variant.

The convergence of dynamic analysis is also affected by the characteristics of the excitations (earthquake timehistory records); earthquake records with high frequency (composed of heavily alternating \pm acceleration values) require more solution time than low-frequency records. Because during the analysis in case of heavy changes in the value of acceleration from - to + and opposite, the solver will divide the original time step into subtime steps to catch the convergence of relevant points; consequently, it will considerably increase the duration of the analysis. For instance, the Duzce earthquake (Figure 6(a)) time-history record has a lower frequency than the Kobe earthquake (Figure 6(b)) with both having a similar duration (around 55 seconds), the same magnitude (around $7.8 \mathrm{~m} / \mathrm{s}^{2}$ ), and the same time step ( 0.01 second). Conducting the dynamic analysis of the concerned FE model under the effect of the Duzce earthquake required 39 hours and 8 minutes, while the same model has been analyzed under the effect of the Kobe earthquake in 50 hours and 16 minutes using the same computer capacity. Smaller time steps generate a more accurate result but require more analysis time. In this study, the time steps of the excitation are 0.01 second which is considered to be the optimum value for seismic analysis.

\subsection{Preliminary Design of the Seismic Elastomeric Isolators.} The preliminary dimension and analytical parameters of the seismic isolators are calculated based on ASCE 7-16 [25] and ASCE 41-13 [26] codes. Yield force (Fv), yield displacement $\left(u_{y}\right)$, damping ratio, and vertical stiffness $(K v)$ are the necessary analytical parameters for finite element modeling of the seismic isolator. Minimum horizontal stiffness and the 


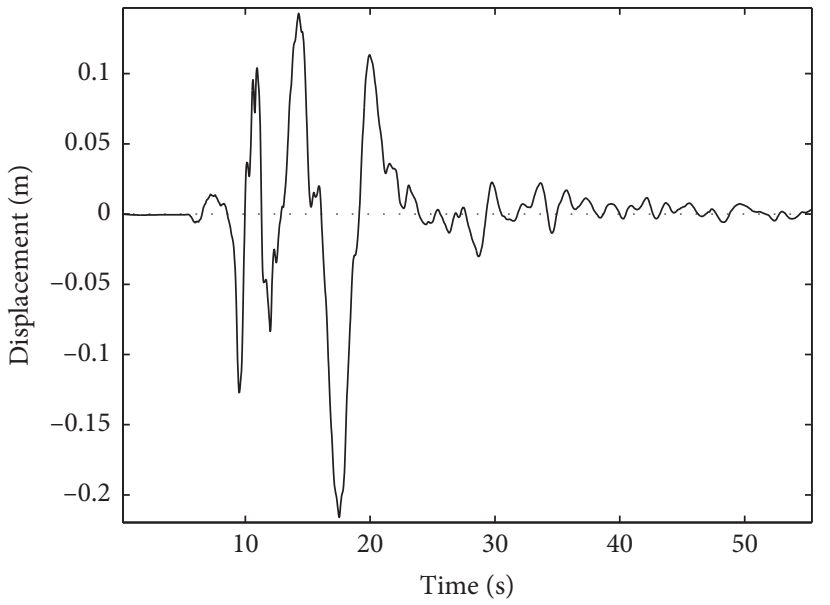

(a)

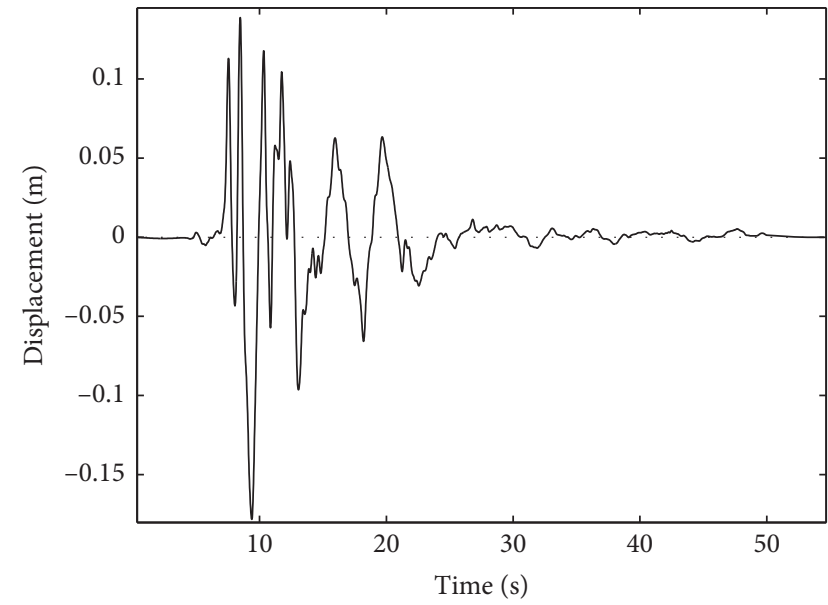

(b)

Figure 6: Displacement time-history records of 1999 Duzce-NS (a) and 1995 Kobe-NS earthquake records.

TABLE 3: Properties of seismic LCRB isolators for SSIS-NC and CAMSBID-NC structures.

\begin{tabular}{lcc}
\hline Parameters & SSIS-NC & CAMSBID-NC \\
\hline K $v(\mathrm{~N} / \mathrm{m})$ & $1.45 E+09$ & $2.93 E+09$ \\
$F_{y}(\mathrm{~N})$ & $2.83 E+05$ & $4.11 E+05$ \\
$K_{h}(\mathrm{~N} / \mathrm{m})$ & $9.67 E+05$ & $1.40 E+06$ \\
Damp $(\%)$ & 0.15 & 0.15 \\
$U_{y}(\mathrm{~m})$ & 0.045 & 0.045 \\
$\Phi($ diameter $)(\mathrm{m})$ & 0.784957 & 1.11 \\
$R_{T}$ (rubber thickness) $(\mathrm{m})$ & 0.5 & 0.5 \\
Number of isolators & 86 & 49 \\
\hline
\end{tabular}

TABLE 4: Ground motion characteristics.

\begin{tabular}{llcccrr}
\hline Earthquake & Year & Station & PGA-X $(\mathrm{g})$ & PGA-Y $(\mathrm{g})$ & Duration $(\mathrm{s})$ & Type \\
\hline Tohoku & 2011 & MYG10 & 0.846 & 0.949 & 300 & Long period \\
El Mayor & 2010 & Chihuahua & 0.248 & 0.196 & 120 & Long period \\
\hline
\end{tabular}

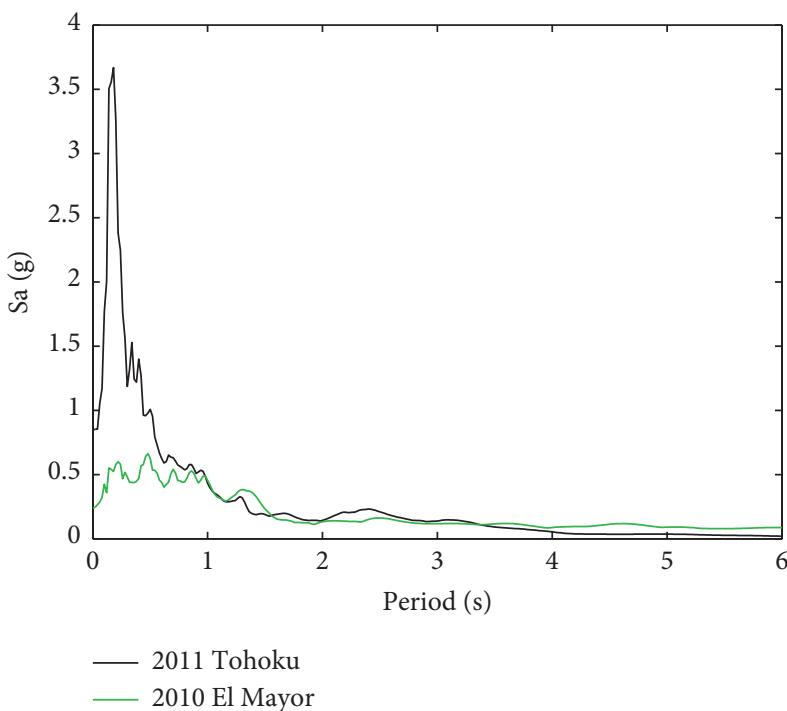

(a)

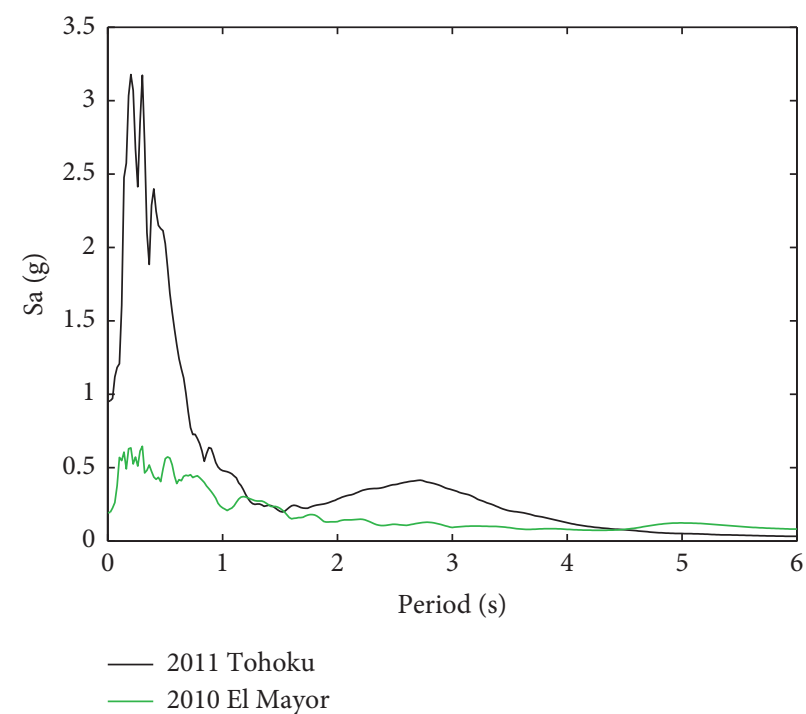

(b)

Figure 7: Spectral acceleration of selected ground motions applied in $X$ (a) and $Y$ (b) directions of the structure. 


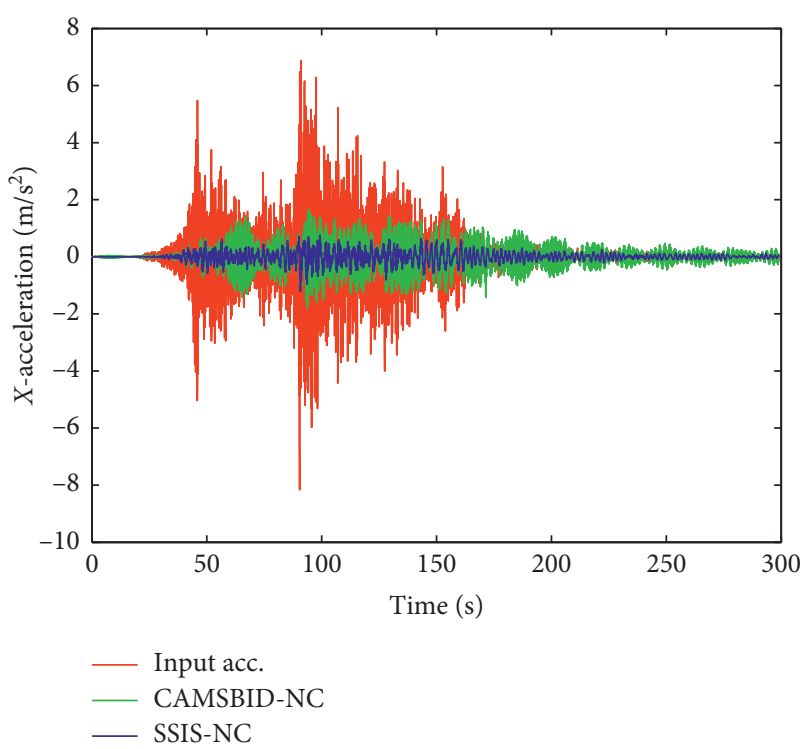

(a)

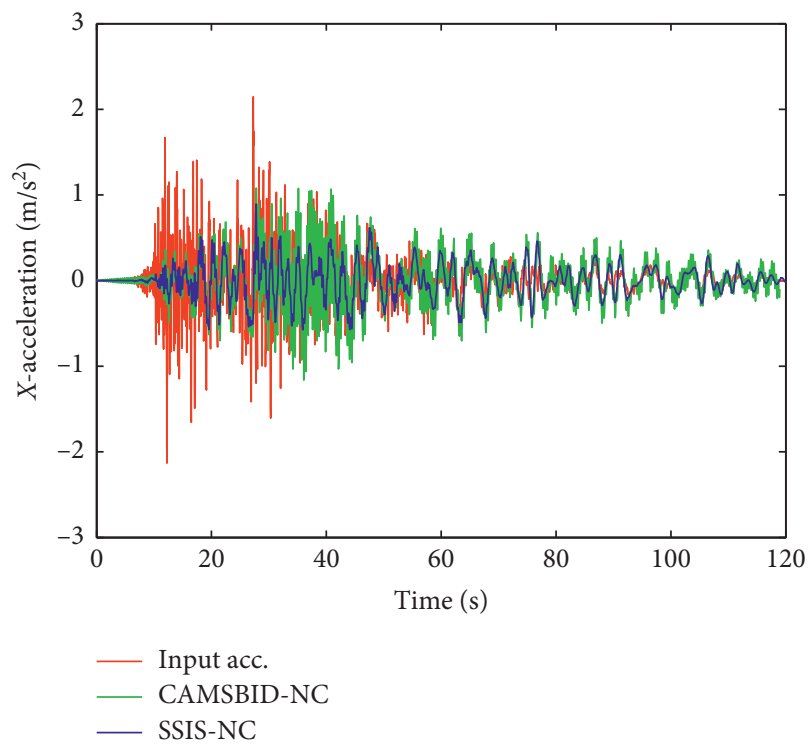

(c)

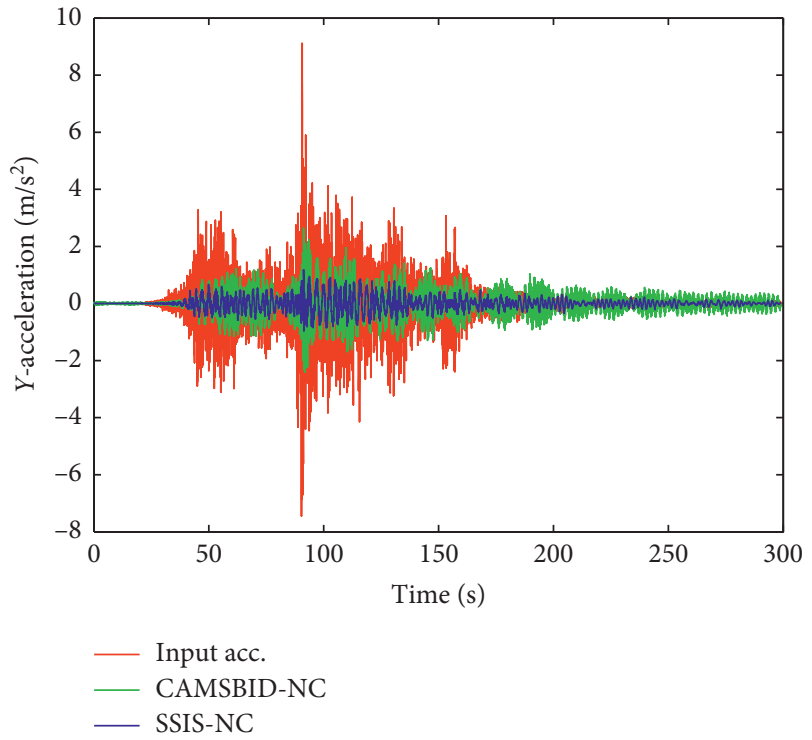

(b)

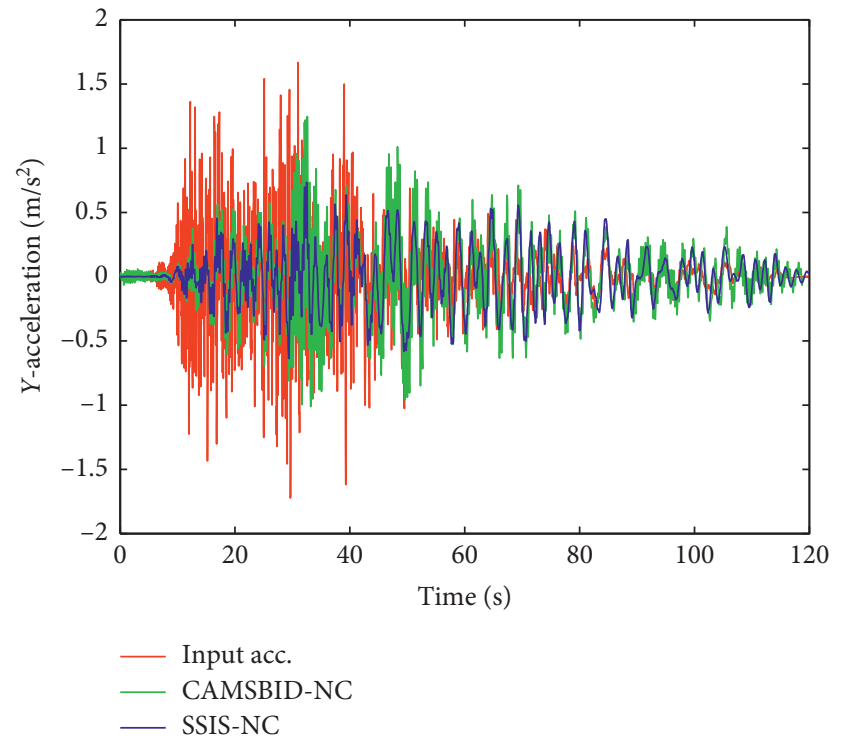

(d)

FIGURE 8: Base-level acceleration responses of SSIS-NC (blue) in comparison with CAMSBID-NC (green) and input acceleration (red) under the effect of 2011 Tohoku (a, b) and 2010 El Mayor (c, d) earthquakes.

design displacement of the isolator are calculated using equations (13) and (14), respectively:

$$
\begin{aligned}
K_{D \min } & =\frac{4 \pi^{2} W}{T_{D}^{2} g}, \\
D_{D} & =\frac{g S_{D 1} T_{D}}{4 \pi^{2} B_{D}},
\end{aligned}
$$

where $W$ stands for the total weight on a single bearing, $T_{D}$ for the design period (here $T_{D}=4$ seconds), $B_{D}$ for the damping coefficient, $g$ for the gravity, and $S_{D 1}$ for the spectral coefficient (the value of $S_{D 1}$ is based on 2011 Tohoku earthquake response spectra). The cross-section area of rubber $\left(A_{r}\right)$ and postyielding stiffness are calculated using equations (15) and (16), respectively:

$$
\begin{aligned}
A_{r} & =\frac{K_{D} t_{r}}{G}, \\
K_{p} & =\frac{G A_{r} f_{L}}{R_{T}} .
\end{aligned}
$$

Yield displacement $\left(u_{y}\right)$ is $0.05 \sim 0.1$ times total rubber thickness $\left(R_{T}\right)$ based on experimental data. $f_{L}$ is a factor that is commonly taken as 1.5 . The characteristic strength $(Q)$ of the elastomeric can be calculated using equation (17). Then, the yield force $\left(F_{y}\right)$ of the bearing can be calculated as equation (18): 


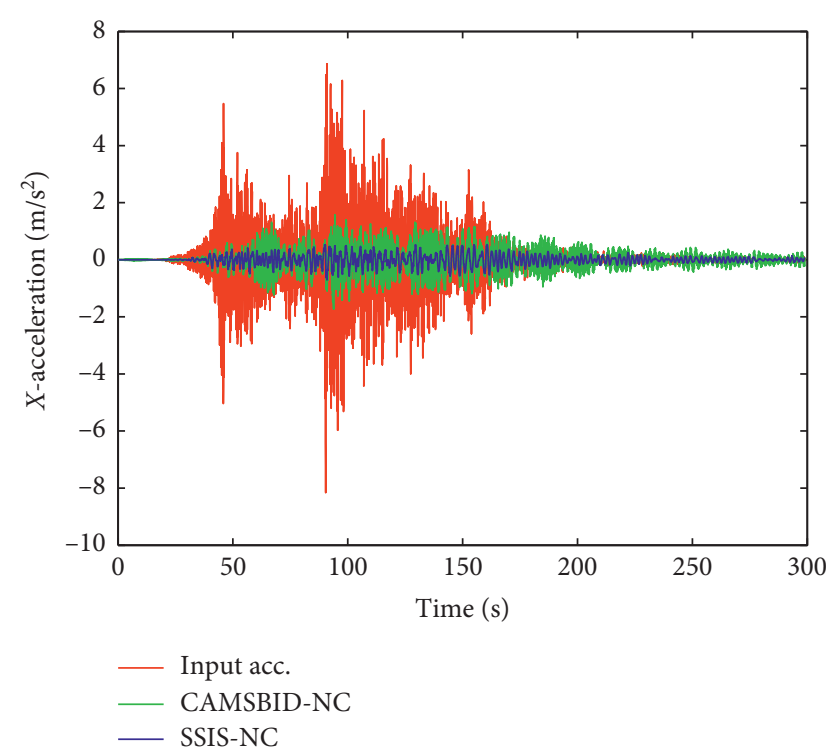

(a)

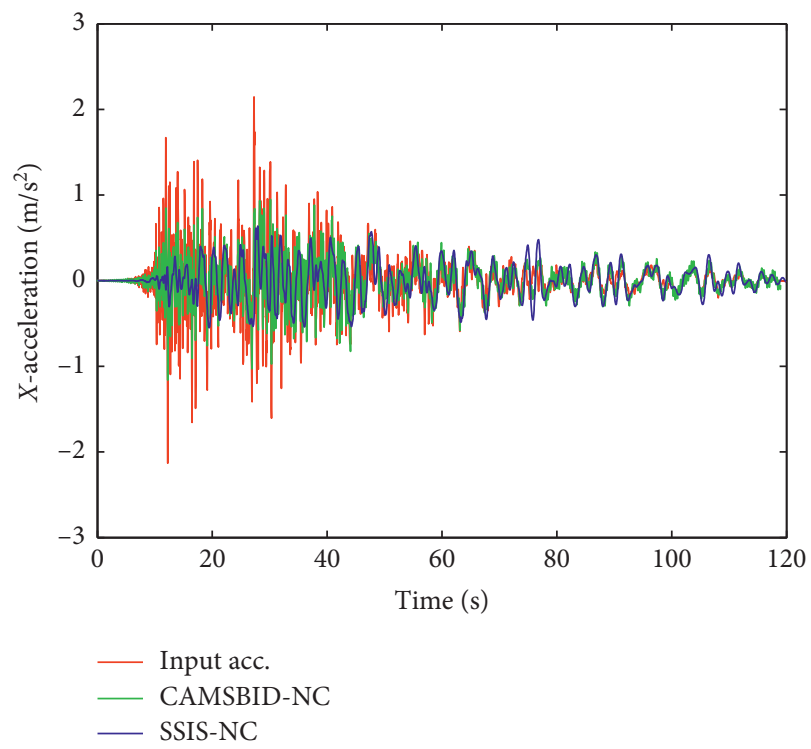

(c)

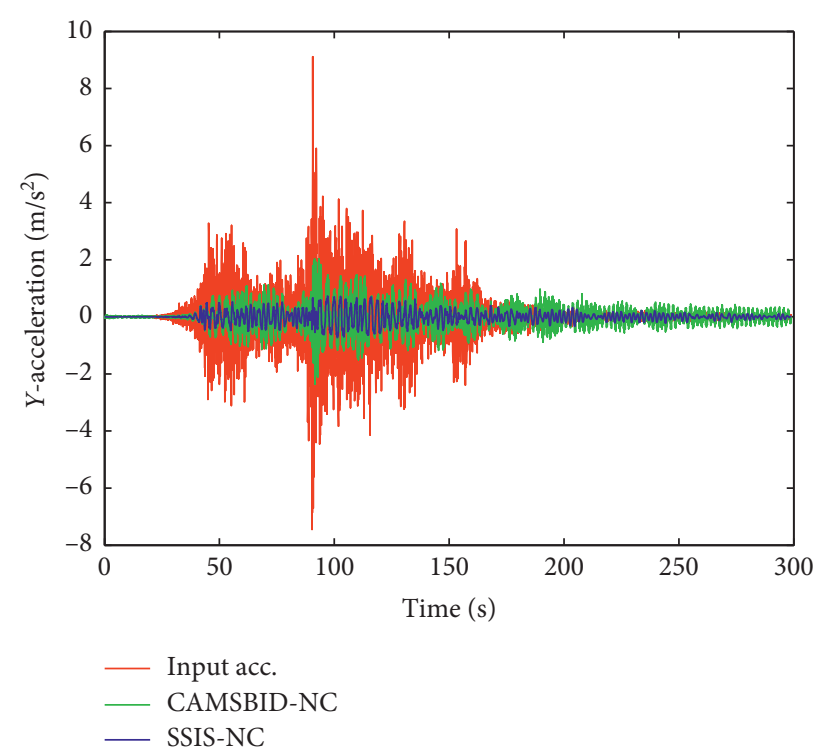

(b)

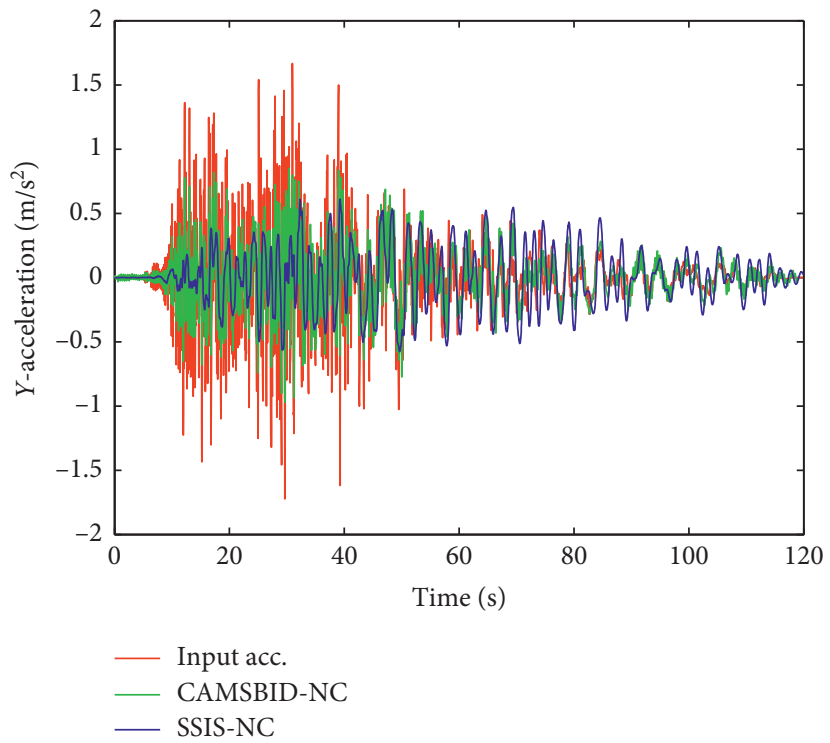

(d)

FIGURE 9: Top-level acceleration responses of SSIS-NC (blue) in comparison with CAMSBID-NC (green) and input acceleration (red) under the effect of 2011 Tohoku (a, b) and 2010 El Mayor (c, d) earthquakes.

$$
\begin{aligned}
& u_{y}=\frac{Q}{5.5 K_{p}}, \\
& F_{y}=Q+K_{p} D_{y} .
\end{aligned}
$$

Finally, the vertical stiffness $(K v)$ of the elastomeric bearing is calculated via equation (19); here, $E_{c}, G$, and $K$ represent the compression of rubber-steel composite, shear, and bulk modulus of rubber, respectively. The value of $K$ and $G$ differs based on the type of rubber; the value of $K$ can vary between 1000 and $2500 \mathrm{MPa}$ and $G$ between 0.45 and $1 \mathrm{MPa}$. $S$ represents the hysteresis loop shape factor of the seismic isolator, and the value of $S$ should range between 12 and 20 [27]. The parameters of the lead core rubber bearing (LCRB) for SSIS-NC and CAMSBID-NC structures are calculated as presented in Table 3:

$$
\begin{aligned}
K_{V} & =\frac{E_{c} A_{r}}{R_{T}}, \\
E_{c} & =\frac{6 G S^{2} K}{6 G S^{2}+K} .
\end{aligned}
$$

The final design of the elastomeric isolator parameters is implemented based on comparing the first iteration results $K_{h}=9.67 E+5^{*} 86=83.162 E+6 \mathrm{~N} / \mathrm{m}$ with the required total horizontal stiffness of the isolators $k_{b}=86.834 E+6 \mathrm{~N} / \mathrm{m}$ obtained from equation (2). Then, it can be confirmed in 


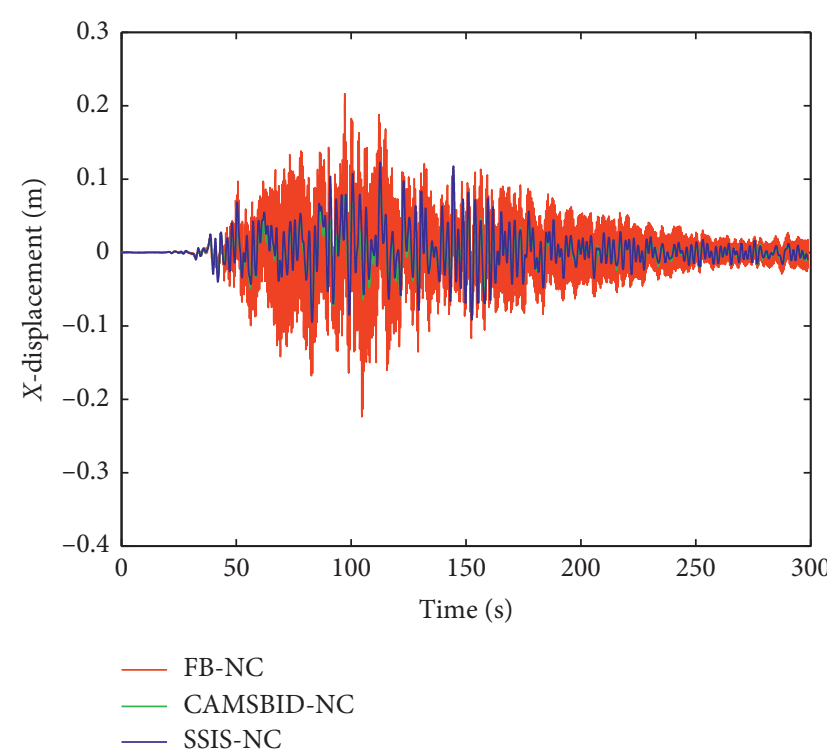

(a)

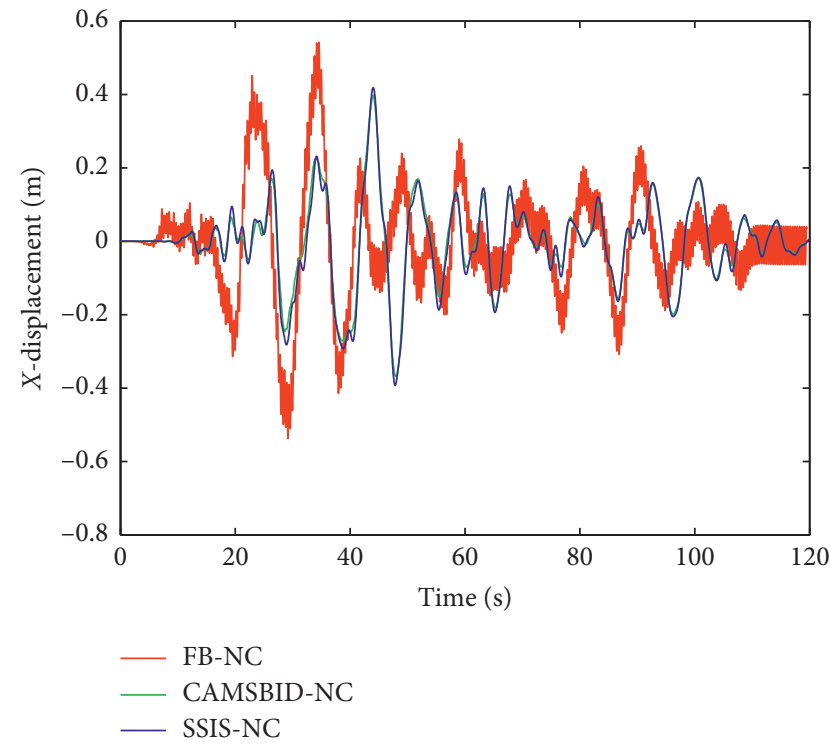

(c)

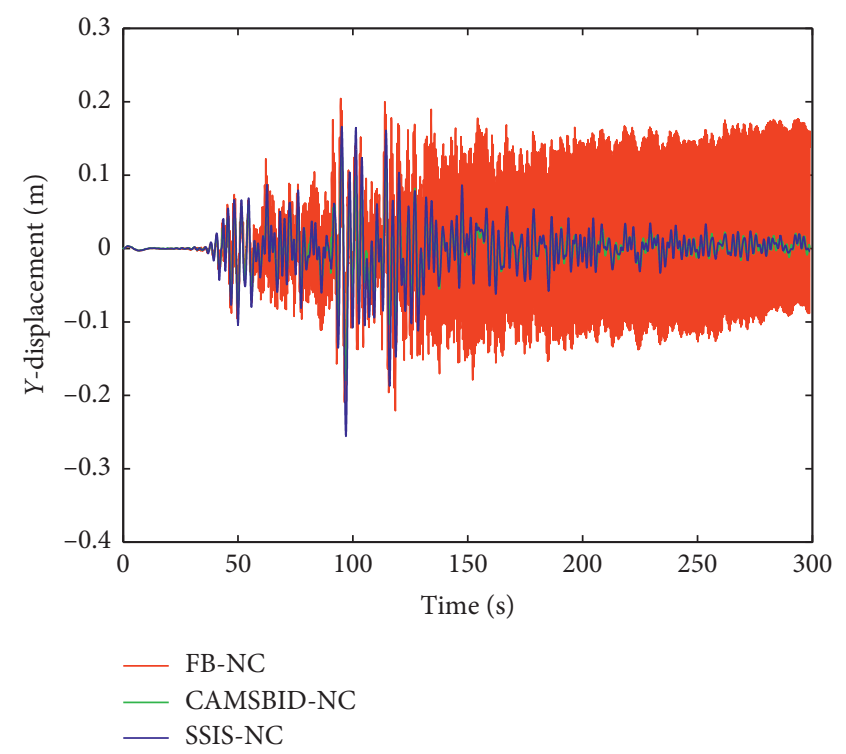

(b)

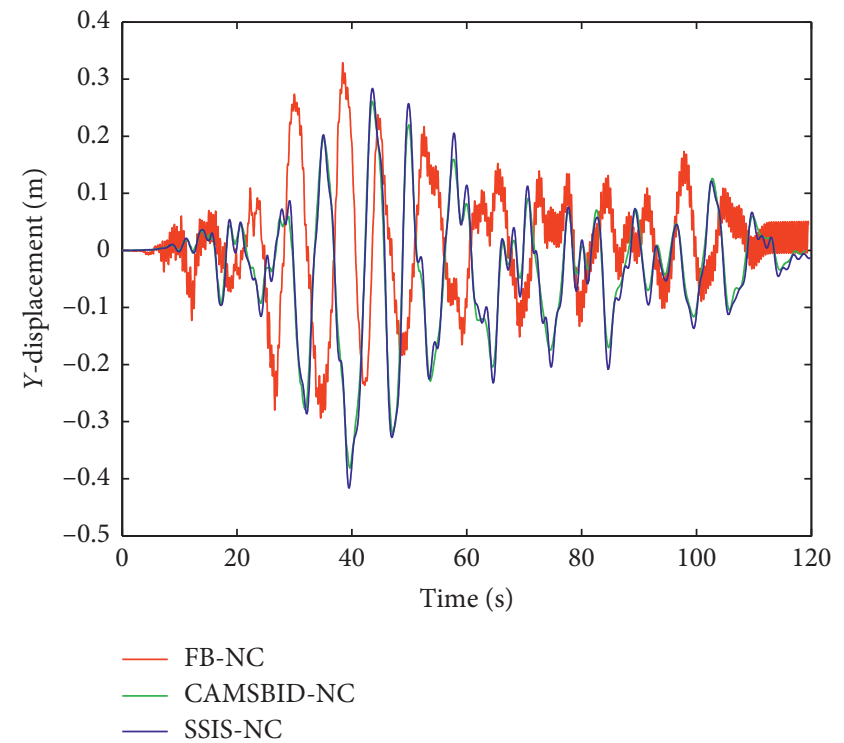

(d)

FIgURE 10: Top-level displacement responses of SSIS-NC (blue) in comparison with CAMSBID-NC (green) and FB-NC (red) under the effect of 2011 Tohoku (a, b) and 2010 El Mayor (c, d) earthquakes.

every iteration by the assessment of the hysteresis loop of the elastomeric isolator.

\section{Numerical Study}

Nonlinear dynamic analysis of the presented finite element model (see Figure 3 ) has been analyzed using two strong and long-period earthquakes; general characteristics of these earthquakes are presented in Table 4 and Figure 7. Time-history data of the ground motions are obtained from the PEER Berkeley Strong Ground Motion database [28]. The design spectrum presented in Figure 7 is used in the preliminary design of the isolator in Section 2.1 .

\section{Results and Discussion}

The base-level and top-level acceleration and the top-level displacement results of the SSIS in comparison with CAMSBID-NC and FB-NC have been presented in Figures 8-10.

Figures $8(\mathrm{a})$ and $8(\mathrm{~b})$ present the base-level acceleration of the models under the effect of the 2011 Tohoku MYG10 earthquake. Similarly, the base-level responses of the models due to the effect of the El Mayor earthquake have been presented in Figures 8(c) and 8(d). Base acceleration results imply that the SSIS-NC model has exhibited a significantly lower response than the CAMSBID-NC model. Top-level accelerations of the models under the effect of the 2011 


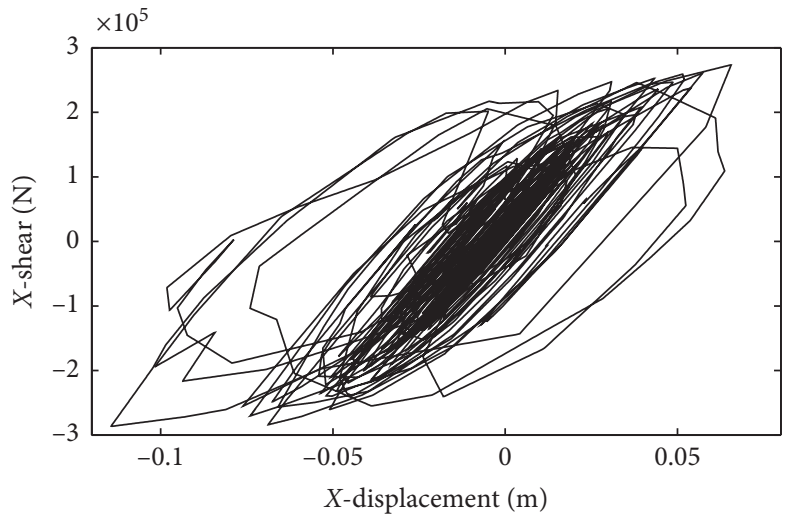

(a)

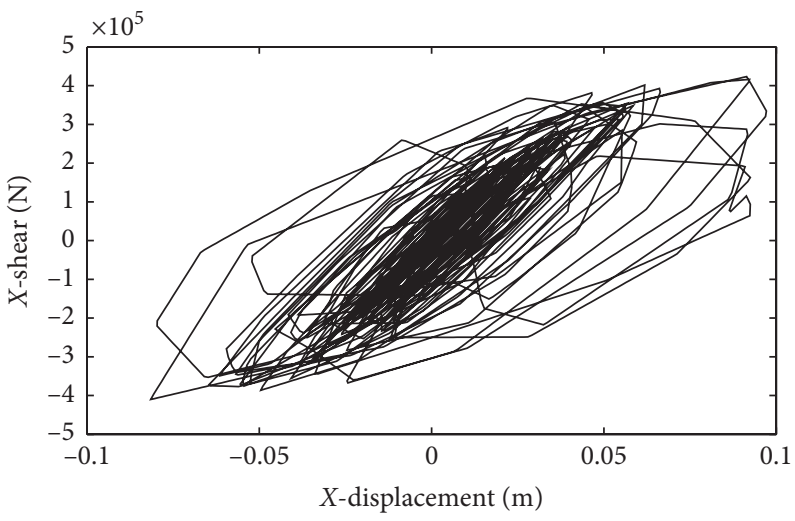

(c)

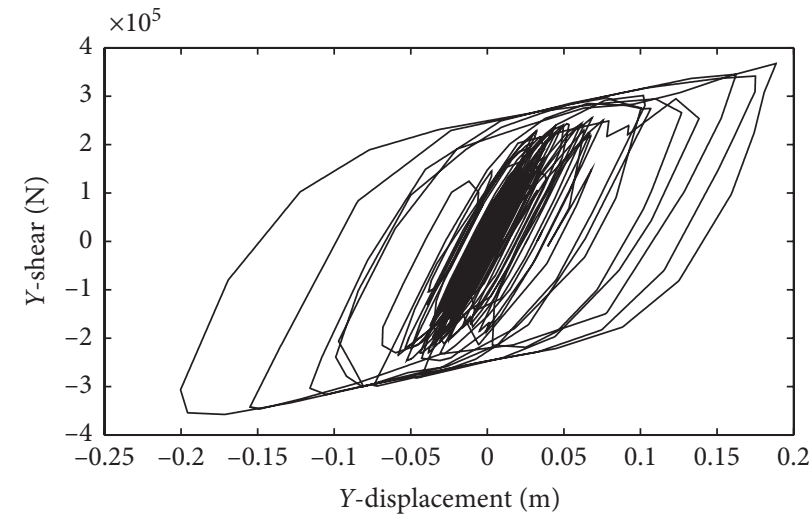

(b)

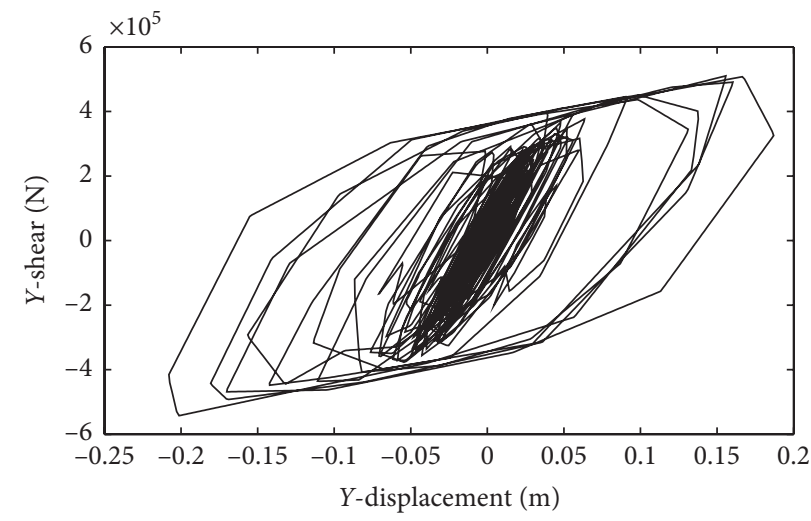

(d)

FIGURE 11: Comparison of the hysteresis loops of the central seismic isolator of SSIS-NC (a, b), CAMSBID-NC (c, d) structures under the effect of the 2011 Tohoku earthquake.

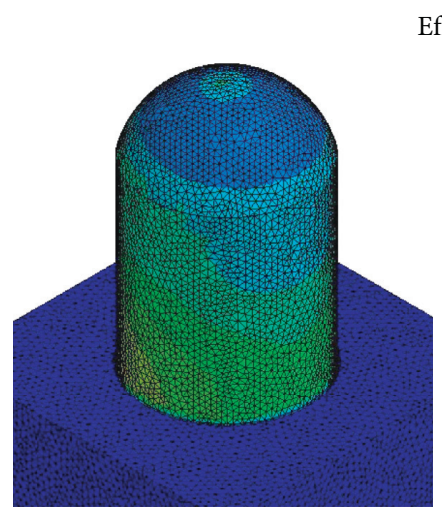

(a)

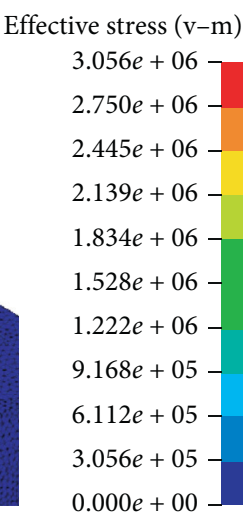

$0.000 e+00$

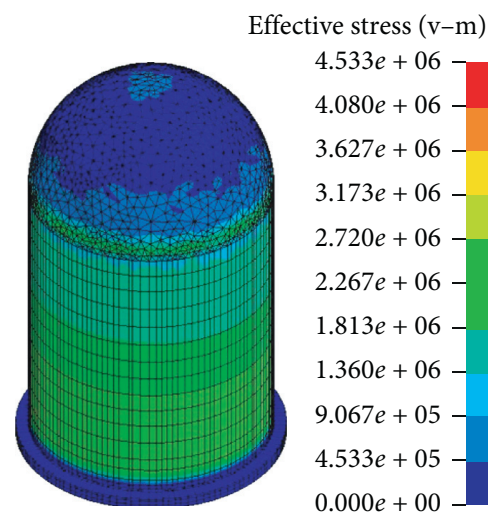

(b)

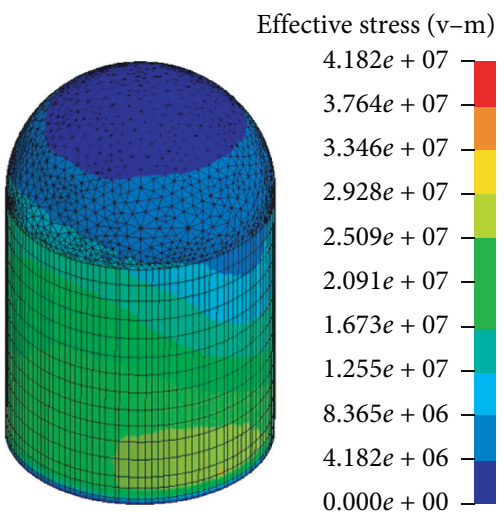

(c)

Figure 12: Comparison of effective stress (Von-Mises) response of SSIS-NC (a), CAMSBID-NC (b), and FB-NC (c) models under the effect of the 2011 Tohoku earthquake.

Tohoku and $2010 \mathrm{El}$ Mayor earthquakes have been presented in Figures 9(a)-9(d), respectively. The top-level results indicate that the SSIS is more effective in mitigating earthquake energy in the top level of the nuclear containment structure compared to that of CAMSBID-NC and FB-NC.

The top-level displacements of SSIS-NC, CAMSBID$\mathrm{NC}$, and FB-NC structures are presented in Figure 10.
Figures 10(a) and 10(b) show the top-level displacement response of the concerned structures under the effect of 2011 Tohoku, and Figures 10(c) and 10(d) present the top-level displacement responses of the same structures under the effect of 2010 El Mayor earthquake. The result clearly indicates the effectiveness of the SISS (Figure 11). 


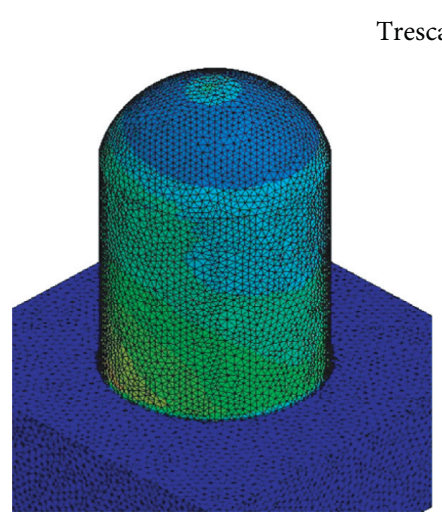

(a)

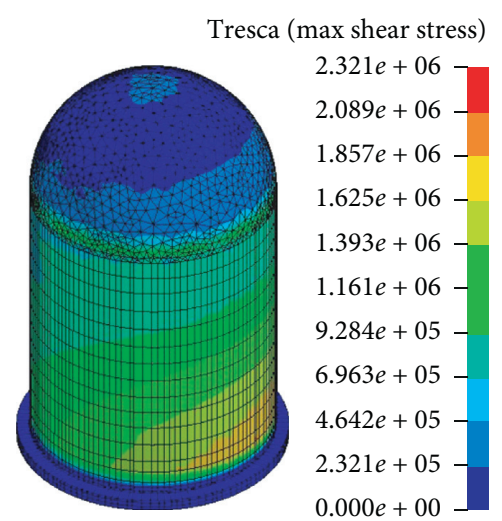

(b)

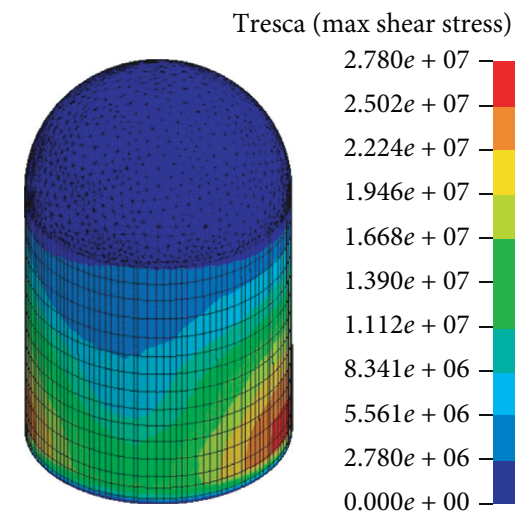

(c)

FIgURE 13: Comparison of critical shear stress (Tresca) response of SSIS-NC (a), CAMSBID-NC (b), and FB-NC (c) models under the effect of the 2011 Tohoku earthquake.

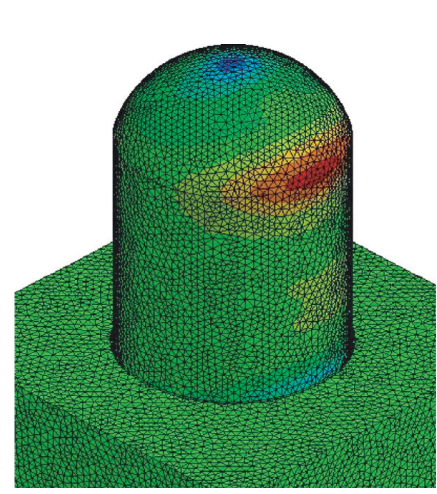

(a)

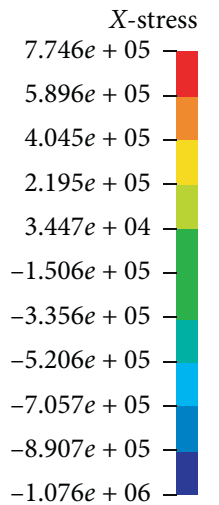

$-1.076 e+06$

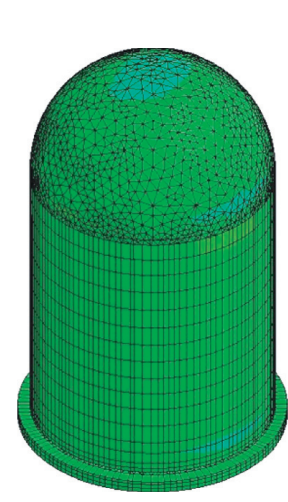

(b)

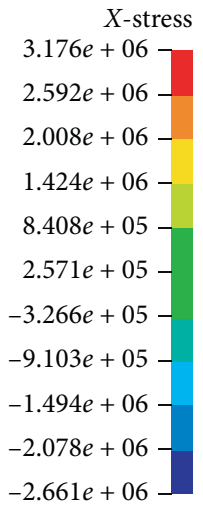

$-2.661 e+06$

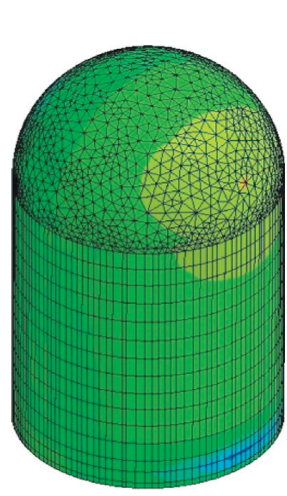

(c)

Figure 14: Comparison of the $X$-stress response of SSIS-NC (a), CAMSBID-NC (b), and FB-NC (c) models under the effect of the 2011 Tohoku earthquake.

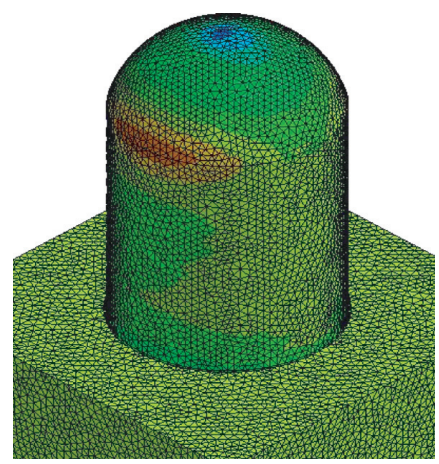

(a)
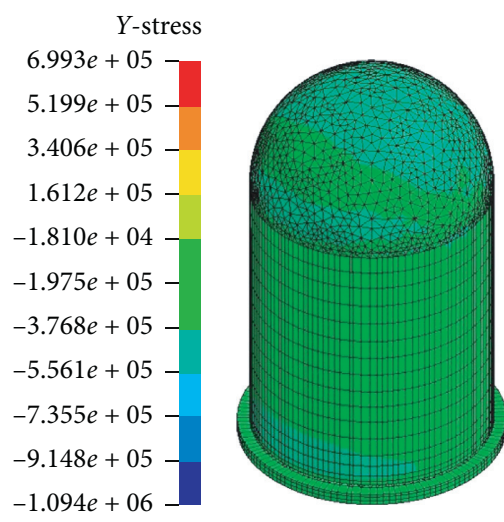

(b)

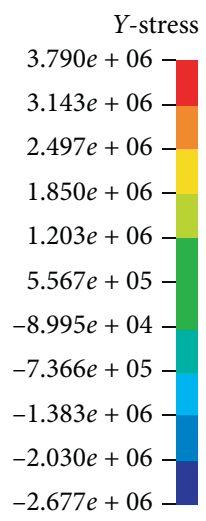

)

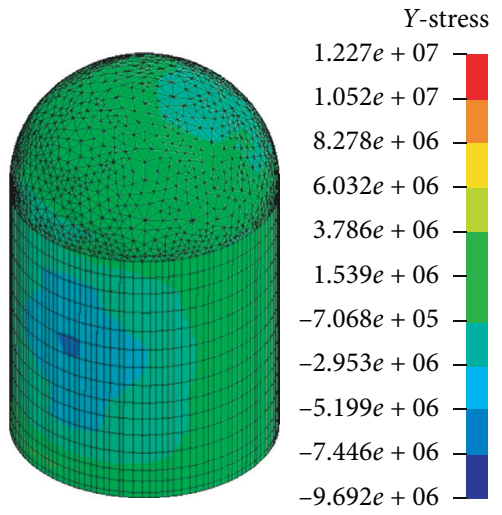

(c)

FIGURE 15: Comparison of the Y-stress response of SSIS-NC (a), CAMSBID-NC (b), and FB-NC (c) models under the effect of the 2011 Tohoku earthquake.

The effective (Von-Mises) stress and critical shear (Tresca) stress responses of SSIS-NC structure are significantly lower than those of CAMSBID-NC and FB-NC structures. It is achieved due to turn around the gyration center of the SSIS-NC structure. The comparison of effective (Von-Mises), critical shear (Tresca), and general $X-Y$ stresses of the SSIS-NC with CAMSBID-NC and FB-NC structures is presented in Figures 12-15. 


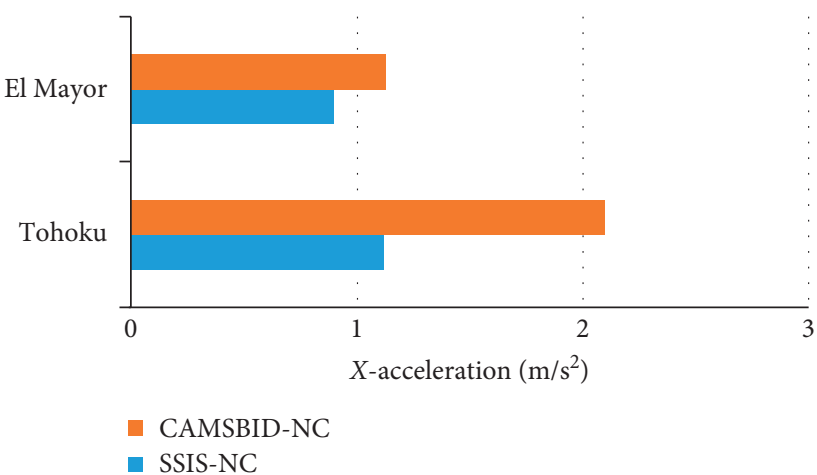

(a)

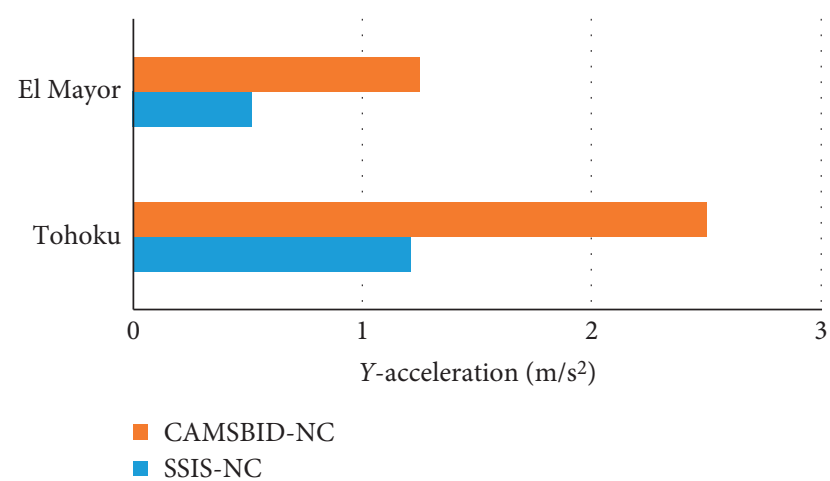

(b)

FIGURE 16: Peak base-level acceleration responses of SSIS-NC and CAMSBID-NC structures.

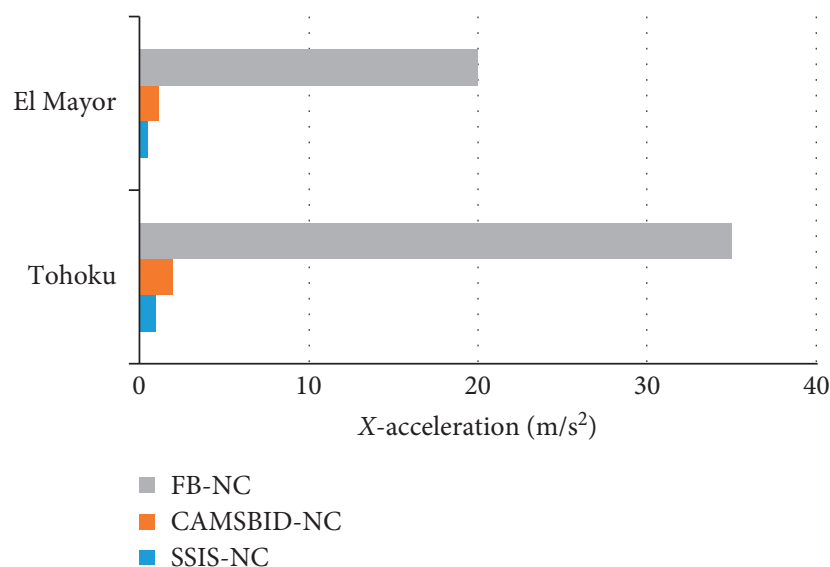

(a)

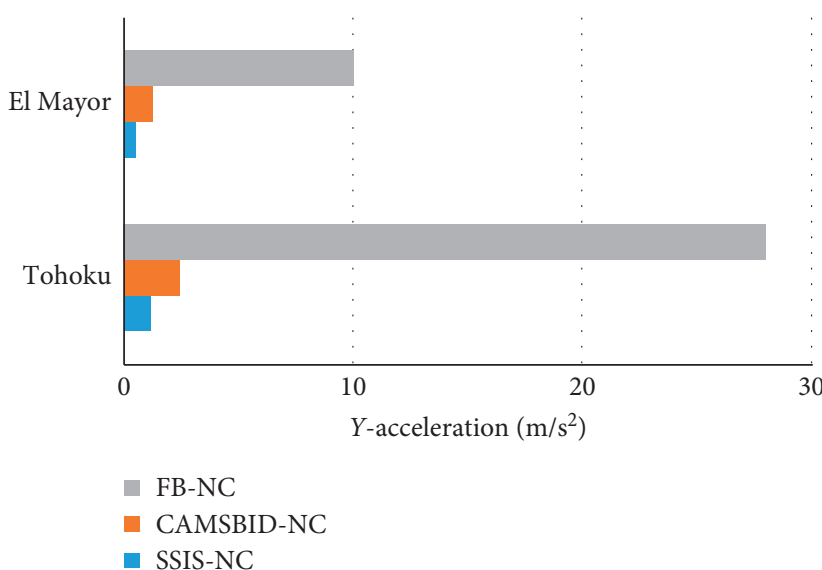

(b)

FIgURE 17: Peak top-level acceleration responses of the SSIS-NC, CAMSBID-NC, and FB-NC structures.

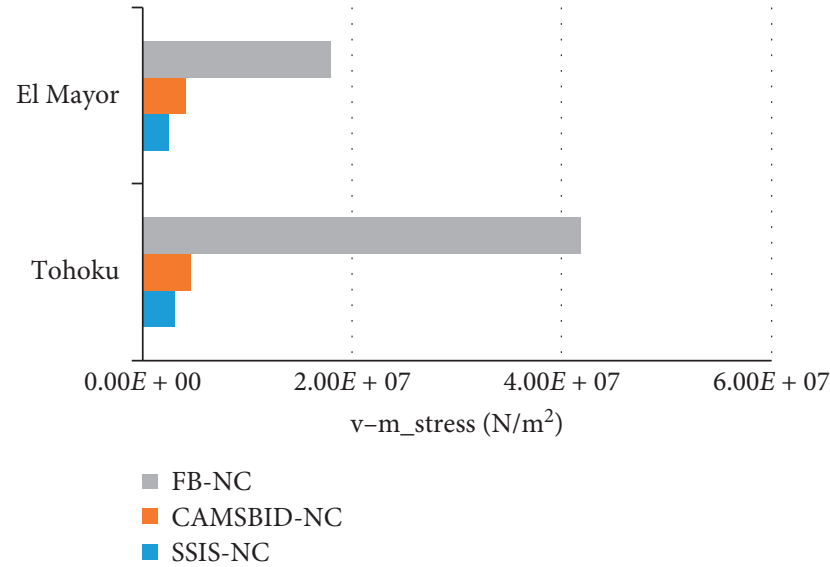

(a)

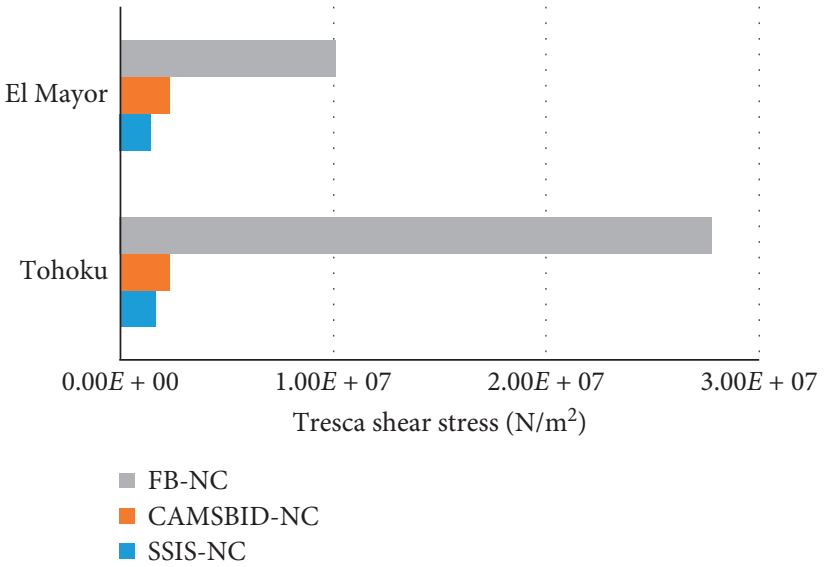

(b)

FIGURE 18: Comparison of peak (a) effective stress (Von-Mises) and (b) critical shear stress (Tresca) responses of the SSIS-NC, CAMSBID$\mathrm{NC}$, and FB-NC structures. 


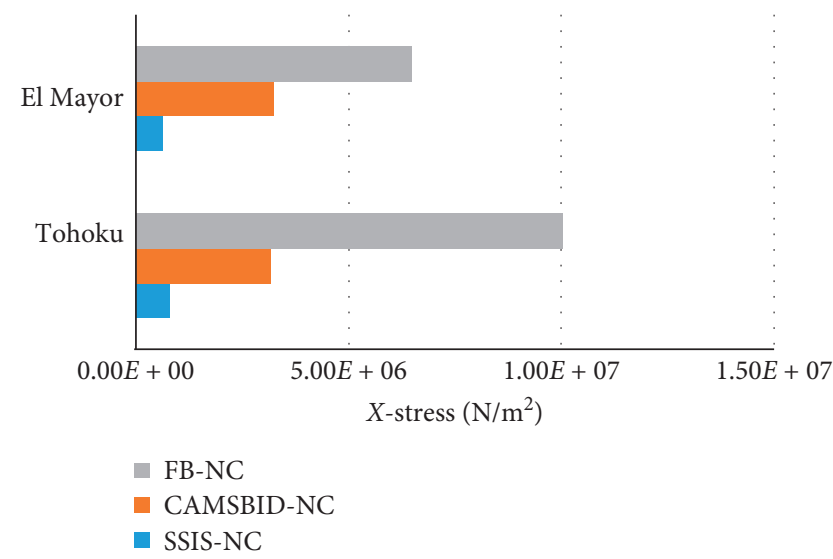

(a)

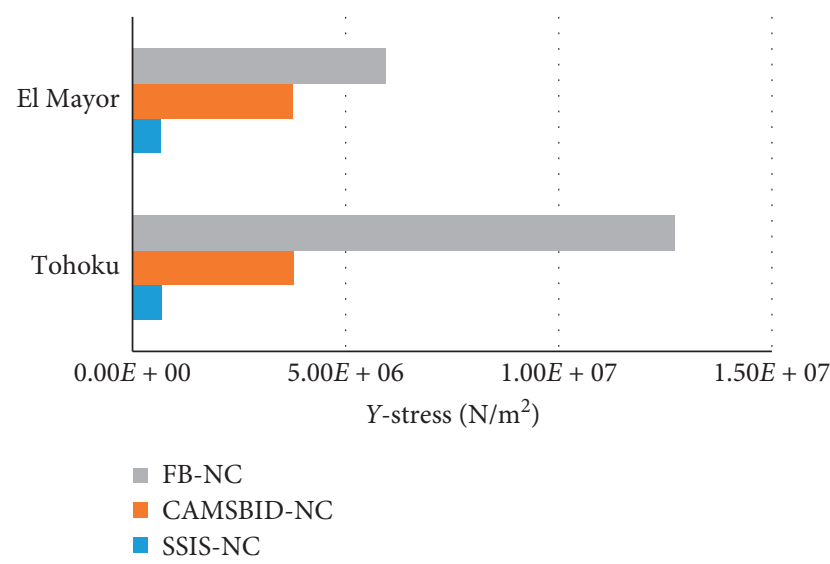

(b)

Figure 19: Comparison of peak $X$-stress (a) and $Y$-stress (b) responses of the SSIS-NC, CAMSBID-NC, and FB-NC structuress.

\section{Conclusions}

The SSIS-NC, CAMSBID-NC, and fixed-base structures were analyzed under the effect of strong and long-period earthquakes listed in Table 4 . The base acceleration responses of the SSIS-NC structure are $33.34 \%$ and $55.10 \%$ lower (on average) than the CAMSBID-NC structure, while there are $52.93 \%$ and $53.33 \%$ differences between the top-level acceleration response of SSIS and CAMSBID-NC structures in the $X$ and $Y$ directions, respectively (see Figures 16 and 17).

The effective stress (Von-Mises) and critical shear stress (Tresca) responses of the SSIS-NC and CAMSBID-NC structures also confirm the effectiveness of the SSIS. As presented in Figure 18, the effective stress and critical shear stress response of SSIS structure are $36.70 \%$ and $32.60 \%$ lower (on average) than CAMSBID-NC structures, respectively. As presented in Figure 19, the general stress responses of SSIS-NC, CAMSBID-NC, and FB-NC structures also indicate the significant effect of the SSIS with a $76.28 \%$ reduction compared to the CAMSBID-NC structure. SSIS:

Therefore, the following aspects can be noted about the

(i) The base and top accelerations, effective stress, and critical shear stress responses of the SSIS-NC structure are $48.67 \%, 36.70 \%$, and $32.60 \%$ (on average) lower than CAMSBID-NC structures, respectively

(ii) The seismic isolator showed maximum performance for the SSIS-NC case compared with CAMSBID$\mathrm{NC}$, while similar seismic isolator parameters were used in the CAMSBID-NC case as well

(iii) There is a possibility of the usage of additional seismic dampers for additional seismic dissipation purposes for extremely important buildings

(iv) The SSIS-NC system can be highly effective and reliable for seismic protection of nuclear containment structure

(v) The feasibility of the usage of this is not limited to nuclear containment structures; it could be used as a seismic protection system for other important structures such as high-rise buildings and offshore oil platform

(vi) The significantly lower response of the SSIS-NC system compared with CAMSBID-NC and FB-NC systems allows to make it even lighter (in the presented study, approximately the same total mass for SSIS-NC, CAMSBID-NC, and FB-NC systems was used only for comparability of the responses)

\section{Data Availability}

The data used to support the findings of this study are available from the corresponding author upon request.

\section{Conflicts of Interest}

The authors declare that they have no conflicts of interest.

\section{Acknowledgments}

This research was supported by the Scientific and Technological Research Council of Turkey (TUBITAK). The support is gratefully acknowledged.

\section{References}

[1] M. Higashino and S. Okamoto, Response Control and Seismic Isolation of Buildings, Taylor \& Francis, London, UK, 1st edition, 2006.

[2] F. Naeim and J. M. Kelly, Design of Seismic Isolated Structures: From Theory to Practice, John Wiley \& Sons, New York, NY, USA, 1999.

[3] A. S. Whittaker, P. Sollogoub, and M. K. Kim, "Seismic isolation of nuclear structures: past, present and future," in Proceedings of 24th Conference on Structural Mechanics in Reactor Technology, August 2017, Busan, South Korea.

[4] A. S. Whittaker, M. Kumar, and M. Kumar, "Seismic isolation of nuclear power plants," Nuclear Engineering and Technology, vol. 46, no. 5, pp. 569-580, 2014.

[5] J. Chen, C. Zhao, Q. Xu, and C. Yuan, "Seismic analysis and evaluation of the base isolation system in AP1000 NI under 
SSE loading," Nuclear Engineering and Design, vol. 278, pp. 117-133, 2014.

[6] ASCE 4-16, Seismic Analysis of Safety-Related Nuclear Structures and Commentary, DOE NPH meeting, American Society of Civil Engineers, Reston, VA, USA, 2016.

[7] ASCE 43-5, Seismic Design Criteria for Structures, Systems, and Components in Nuclear Facilities, American Society of Civil Engineers, Reston, VA, USA, 2005.

[8] RCC-CW, "Rules for design and construction of PWR nuclear civil works," in AFCEN 2016, 2016, https://afcen.com/en/ publications/rcc-cw/104/rcc-cw-2016.

[9] N. Behling, M. C. Williams, T. G. Behling, and S. Managi, "Aftermath of Fukushima: avoiding another major nuclear disaster," Energy Policy, vol. 126, pp. 411-420, 2019.

[10] N. Ostrovskaya and Y. Rutman, "Optimum control of energy dissipation in support-pendulum seismic isolation system for large NPP equipment," Procedia Structural Integrity, vol. 6, pp. 19-26, 2017.

[11] C. Medel-Vera and T. Ji, "Seismic risk control of nuclear power plants using seismic protection systems in stable continental regions: the UK case," Nuclear Engineering and Design, vol. 307, pp. 377-391, 2016.

[12] A. S. Whittaker, P. Sollogoub, and M. K. Kim, "Seismic isolation of nuclear power plants: past, present and future," Nuclear Engineering and Design, vol. 338, 2018.

[13] A. A. Kasimzade, E. Şafak, C. E. Ventura, F. Naeim, and Y. Muka, Seismic Isolation, Structural Health Monitoring, and Performance Based Seismic Design in Earthquake Engineering: Recent Developments, Springer, Berlin, Germany, 2018.

[14] A. A. Kasimzade, E. Tachibana, Y. Mukai et al., "Spherical foundation base isolation system on base ancient architecture inherence," in Proceedings of the International symposium on disaster simulation, DS'15, pp. 127-133, Osaka, Japan, June 2015.

[15] A. A. Kasimzade, E. Tachibana, Y. Mukai et al., "Spherical foundation structural seismic isolation system: development of the new type earthquake resistant structures," in Proceedings of the 6 th International Conference on Theoretical and Applied Mechanics (TAM'15), pp. 287-292, Salerno, Italy, June 2015.

[16] A. A. Kasimzade, O. Abrar, S. Tuhta, and G. Atmaca, "Investigation of seismic base isolated structures for long period ground motions," International Journal of Engineering and Applied Sciences, vol. 5, no. 6, pp. 812-818, 2018.

[17] A. A. Kasimzade, Finite Element Method: Foundation and Application to Earthquake Engineering (Including Educational Finite Element Analysis Software CD-MATLAB Codes), Nobel Publication, Istanbul, Turkey, 2018.

[18] F. Ikhouane and J. Rodellar, Systems with Hysteresis: Analysis, Identification and Control Using the Bouc-Wen Model, John Wiley \& Sons, Hoboken, NJ, USA, 2007.

[19] Y. K. Wen, "Method for random vibration of hysteretic systems," Journal of Engineering Mechanics Division, vol. 102, no. 2, pp. 249-264, 1976.

[20] A. Ali, N. Abu-Hayah, D. Kim, and S. G. Cho, "Design response spectra-compliant real and synthetic GMS for seismic analysis of seismically isolated nuclear reactor containment building," Nuclear Engineering and Technology, vol. 49, no. 4, pp. 825-837, 2017.

[21] J. Liu, J. Kong, and X. Kong, "Shaking table model tests of concrete containment vessel (CCV) for CPR1000 nuclear power plant," Progress in Nuclear Energy, vol. 93, pp. 186-204, 2016.
[22] LSTC, LS-DYNA keywords User Manual Livermore Software Technology Corporation, LSTC, Livermore, CA, USA, 2013.

[23] J. O. Hallquist, LS-DYNA Theory Manual, Livermore Software Technology Corporation, Livermore, CA, USA, 2006.

[24] S. Nagarajaiah, A. M. Reinhorn, and M. C. Constantinou, "Nonlinear dynamic analysis of 3-D-base-isolated structures," Journal of Structural Engineering, vol. 117, no. 7, pp. 20352054, 1991.

[25] ASCE 7-16, Minimum Design Loads for Buildings and Other Structures, American Society of Civil Engineers, Reston, VA, USA, 2016.

[26] ASCE 41-13, Seismic Evaluation and Retrofit of Existing Buildings, American Society of Civil Engineers, Reston, VA, USA, 2013.

[27] F. Naeim, The Seismic Design Handbook, Springer, New York, NY, USA, 2003.

[28] PEER, Pacific Earthquake Engineering Research Center Ground Motion Database, Berkeley University, Berkeley, CA, USA, 2016. 